NBER WORKING PAPER SERIES

\title{
A QUANTITATIVE ANALYSIS OF DISTORTIONS IN MANAGERIAL FORECASTS
}

\author{
Yueran Ma \\ Tiziano Ropele \\ David Sraer \\ David Thesmar \\ Working Paper 26830 \\ http://www.nber.org/papers/w26830 \\ NATIONAL BUREAU OF ECONOMIC RESEARCH \\ 1050 Massachusetts Avenue \\ Cambridge, MA 02138 \\ March 2020
}

We thank seminar participants at ASSA, Princeton University, UIUC, UC Berkeley, Boston College, Brandeis, Chicago, Dartmouth, MIT, UCLA and SITE for their insightful comments. The views expressed here should not be interpreted as representing the views of the Bank of Italy or any other institution with which the authors are affiliated. The views expressed herein are those of the authors and do not necessarily reflect the views of the National Bureau of Economic Research.

NBER working papers are circulated for discussion and comment purposes. They have not been peer-reviewed or been subject to the review by the NBER Board of Directors that accompanies official NBER publications.

(C) 2020 by Yueran Ma, Tiziano Ropele, David Sraer, and David Thesmar. All rights reserved. Short sections of text, not to exceed two paragraphs, may be quoted without explicit permission provided that full credit, including $(\odot$ notice, is given to the source. 
A Quantitative Analysis of Distortions in Managerial Forecasts

Yueran Ma, Tiziano Ropele, David Sraer, and David Thesmar

NBER Working Paper No. 26830

March 2020

JEL No. E03,E22,E7,E70,E71,G02,G3,G31

\begin{abstract}
$\underline{\text { ABSTRACT }}$
This paper quantifies the economic costs of distortions in managerial forecasts. We match a unique managerial survey run by the Bank of Italy with administrative data on firm balance sheets and income statements. The resulting dataset allows us to observe a long panel of managerial forecast errors for a sample of firms representative of the Italian economy. We show that managerial forecast errors are positively and significantly autocorrelated. This persistence in forecast error is consistent with managerial underreaction to new information. To quantify the economic significance of this forecasting bias, we estimate a dynamic equilibrium model with heterogeneous firms and distorted expectations. The estimated model matches not only the persistence of forecast errors, but the empirical link between investment and managerial forecasts. Relative to a counterfactual with rational expectations, we find that managers exhibit large forecasting biases, which lead to significant distortions in firm-level investment. These distortions, however, imply limited loss in firm value. In general equilibrium, the estimated model leads to negligible aggregate efficiency losses from distorted forecasts.

Yueran Ma

The University of Chicago

Booth School of Business

5807 S. Woodlawn Ave.

Chicago, IL 60637

United States

Yueran.Ma@chicagobooth.edu

Tiziano Ropele

Bank of Italy

Economic Research Unit, Milano Branch

Via Cordusio, 5

20123 Milano

Italy

tiziano.ropele@bancaditalia.it

David Sraer

Haas School of Business

University of California, Berkeley

545 Student Services Building

Berkeley, CA 94720-1900

and NBER

sraer@berkeley.edu

David Thesmar

MIT Sloan

100 main street

02478 Cambridge MA

thesmar@mit.edu
\end{abstract}




\section{Introduction}

This paper quantifies the effect of biases in managerial forecasts on corporate investment, firm value and aggregate efficiency. Several studies have convincingly documented the existence of systematic biases in managerial decision-making. In a large sample of newly-created French firms, Landier and Thesmar (2009) show that managerial optimism correlates with short-term leverage. In a different context, Malmendier and Tate (2005) analyze a sample of publicly traded US firms and establish that overconfident managers overpay for acquisitions and find a strong positive relation between the sensitivity of investment to cash flow and executive overconfidence. Similarly, Hirshleifer et al. (2012) document that overconfident managers invest more in innovation and achieve greater innovative success for given $R \& D$ expenditures. A nascent, related, literature emphasizes the importance of systematic errors in managerial forecasting. Using a survey of large public US firms, Ben-David et al. (2013) provide evidence that CEOs exhibit miscalibrated expectations of aggregate stock market returns, and that, in the cross-section of firms, CEO overconfidence measures correlate with investment and leverage. Using US CFO survey data, Gennaioli et al. (2016) document that managerial expectations tend to be extrapolative, and that expectations have strong explanatory power for firm investment. While these papers establish a statistically significant relationship between systematic forecast errors and managerial decisions, our paper asks whether such forecasting biases matter quantitatively. Do they create significant distortions in firm-level decisions? Do they contribute significantly to aggregate inefficiency?

Our paper answers these questions in two steps. First, we introduce new, high quality data to study managerial expectations. We use a representative, annual business survey run by the Bank of Italy that asks firms about their forecasts of one-year ahead sales. Since 2002, the sample contains about 4,000 firms per year with at least 20 employees. We match this sample with administrative data on firms' balance sheets and income statements. The resulting dataset allows us to analyze the determinants of (sales) forecast errors and their connection with actual corporate behavior. Second, we combine reduced-form empirical evidence and a structural dynamic model to quantify the economic implications of distortions in managerial forecasts. As discussed above, standard analyses in the literature usually provide reduced-form

evidence showing that biases in managerial forecasts affect firm-level decisions, e.g., financing or investment. These analyses are, however, mostly silent on how much these distortions impair firm value or aggregate economic efficiency. In contrast, our 
structural approach builds on such reduced-form evidence and allows us to compare the economy we observe in the data - which potentially features distorted beliefs with a counterfactual economy where agents hold rational expectations.

Our analysis starts with reduced-form evidence of systematic biases in managerial forecasts. Our approach is similar to recent contributions in the macroeconomics and finance literature that investigates the dynamics of beliefs using survey data. ${ }^{1}$ In particular, we show that, in our representative panel of Italian firms, managerial forecasting errors are highly persistent. The autocorrelation coefficient of sales forecast errors is .32 in our preferred specification and is strongly statistically significant. This persistence in forecast errors holds even when controlling for firm fixed-effects and is stable across firm size quintiles and across industries. This result is consistent with the hypothesis that managers underreact to news about their own sales. Intuitively, in period $t$ a positive shock about a firm's sales generates a positive forecast error in the same period. If the manager underreacts to this news and sales are persistent, the $t+1$ forecast will be too low on average, giving rise to another positive forecast error in the next period. Thus, underreaction to news leads to positive autocorrelation of forecast errors.

We then develop an economic framework to quantify the effect of forecasting biases. We start from a standard neoclassical model of investment with heterogeneous firms, similar to David and Venkateswaran (2019) with the addition that managers may not process information efficiently. Production takes place through a standard Cobb-Douglas technology that combines labor and capital. Firm-level productivity follows an AR(1) process. Every period, managers observe the realization of productivity and a private signal informative about next-period productivity. Firms face a one period time-to-build for capital investment, so that current capital expenditures decisions depend on managerial forecasts about future productivity. In contrast to the standard neoclassical model, these forecasts need not be rational. We extend the formulation of belief formation in Bordalo et al. (2017) to accommodate both over- and underreaction to news about firms' productivity: managers can either extrapolate the news contained in the current innovation to productivity (the belief distortion emphasized in Bordalo et al. (2017)), or instead fail to fully account for its news content. ${ }^{2}$

\footnotetext{
${ }^{1}$ See, for instance, the recent works by Coibion and Gorodnichenko (2015), Bordalo et al. (2017), Bordalo et al. (2019), Malmendier and Nagel (2016), Bouchaud et al. (2018).

${ }^{2}$ We emphasize a behavioral interpretation of the persistence in forecast errors. Another interpretation could rely on noisy information models (e.g., Coibion and Gorodnichenko (2015)). However, in our context, we know that managers observe their firm's realized sales, making this interpretation less appealing.
} 
In addition to time-to-build, our model make two additional assumptions: (1) firms face quadratic adjustment costs to capital, and (2) forecasts may be observed with measurement error. We introduce these ingredients in the model to account for an important feature of the data. With a Cobb-Douglas production function and no adjustment costs, the elasticity of capital to sales forecast is equal to 1 . In the data, this elasticity is about .4. Both adjustment costs and measurement error in the forecast have the potential to break the unit elasticity, and allow the model to match the empirical relationship between news and corporate actions.

We estimate the model using a simulated method of moment. Our estimation targets three key features of the data. The first set of moments relates to firm-level production. We match the productivity process observed in the production data, as well as the autocorrelation of investment to identify capital adjustment costs. The second set of moments characterizes managerial expectations. The estimation targets the persistence in sales forecast errors that we document in the first part of the paper. It also targets the variance of sales forecast errors to measure private information, a key driver of empirical managerial forecasts that our model seeks to account for. The final moment we use is the elasticity of capital to sales forecasts, which allows to pin down the "noise" in empirical forecasts, which our model also accounts for. Consistent with the reduced-form evidence, our estimated structural model indicates the presence of large distortions in forecasting compared to the rational expectations benchmark. When forecasting date $t+1$ productivity, we estimate that managers assign a weight on date $t$ productivity shock that is less than half of that for a rational manager. Relative to the rational expectations benchmark, we find that the estimated underreaction leads to an increase in the variance of sales forecast errors of $14.63 \%$.

This underreaction to news about productivity leads to significant distortions in firm-level investment. For a productivity shock at the 75th percentile of the distribution, the average manager in the data under-invests by $10.01 \%$ relative to the rational expectation counterfactual. Symmetrically, for a productivity shock at the 25 th percentile, the inattentive manager over-invest by $16.72 \%$ relative to the rational manager. These large distortions on investment lead, however, to limited reduction in firm value: in the counterfactual where managers hold rational expectations, firm value is only $0.65 \%$ larger. This result emanates in part because, in our model, firms select their capital stock to optimize their value without any additional constraints. As a result, at the optimum, first-order deviations in investment only have secondorder effects on firm value. ${ }^{3}$ The effect of distorted forecasts is further dampened in

\footnotetext{
${ }^{3}$ This finding remains, of course, a quantitative result: larger distortions in forecasts than the ones
} 
general equilibrium, as equilibrium prices mediate the inefficiencies induced by belief distortions: in a rational equilibrium counterfactual, aggregate TFP is only 0.08 $\%$ higher than in the data. While statistically significant, and economically sizable when focusing on investment, the managerial underreaction we document in the data has almost negligible effects in terms of aggregate efficiency.

Our paper builds on a recent literature that uses forecast data to test rationality. Coibion and Gorodnichenko (2015) show that past revisions positively predict forecast errors in consensus macroeconomic forecasts. They argue that this predictability arises from informational frictions. Bouchaud et al. (2018) document underreaction among stock analysts. Also looking at stock analysts, Bordalo et al. (2019) show that forecast errors on long-term EPS growth forecasts are positively correlated with past growth, suggesting overreaction. Bordalo et al. (2018) find overreaction in macro and financial variables at the individual level among professional forecasters. Bloom et al. (2017) show that $15 \%$ of plant managers cannot form and express subjective probability distributions. Using data on household expectations of inflation, Malmendier and Nagel (2016) find evidence consistent with "experience effects": heavy discounting of pre-birth data combined with recency bias. We contribute to this literature by documenting significant underreaction to new information in managerial forecast data. More importantly, our paper provides a tractable framework to quantify the economic effects of this forecasting bias. We incorporate non-rational forecasts into an otherwise standard neoclassical model of investment with heterogeneous firms. The structural approach is necessary to construct a rational expectation counterfactual.

Through its aggregation approach, our paper also relates to a small number of papers that investigate the impact of managerial information on long-term output in steady state models. On the theory side, Akerlov and Yellen (1985) show that, in most equilibrium settings, near-rational behavior can have first-order aggregate consequences, even when it has second-order individual effects. Hassan and Mertens (2017) build on Akerlov and Yellen (1985) and show that near-rational errors lead to first-order distortions in household savings decisions. On the empirical side, David et al. (2016) develop a steady-state production model similar to ours, but use it to quantify aggregate efficiency improvements that result from a well-developed stock market. David and Venkateswaran (2019) employ a similar model to investigate the effect of information frictions (imperfect information about future productivity). Notably, these last two papers do not use forecast data and instead assume rationality. we estimate in the data could definitely result in large distortions in firm value. 
We find that, in addition to information frictions, expectations feature underreaction to news, which our model matches and quantifies. In parallel work, Barrero (2018) uses expectation survey data to calibrate the economic effect of managerial forecasts biases that he identifies in the data. Also related to our paper is Giglio et al. (2019), who analyze the relationship between stock market returns forecasts and the risky share in investors' portfolios. They find a positive and statistically significant relationship, but the magnitude is smaller than what one would expect in a frictionless model. In our sample of firms, we find the relationship between sales expectations and investment to be significant, but also much smaller than what one would expect in a frictionless model.

The rest of the paper is organized as follow. Section 2 presents reduced-form evidence of persistence in managerial forecast errors. Section 3 builds a production framework with heterogeneous firms and distorted expectations, provides a structural estimation of the model, and quantifies a number of partial equilibrium counterfactuals. Section 4 provides aggregation results. Section 7 concludes.

\section{Evidence on Managerial Biases}

\subsection{Data and Summary Statistics}

\section{Sample}

Our main data come from the Survey on Industrial and Service Firms (INVIND, henceforth), which is a large annual business survey conducted by the Bank of Italy on a representative sample of firms. Since 2002, the reference universe in INVIND consists of firms with at least 20 employees operating in industrial sectors (manufacturing, energy, and extractive industries) and in non-financial private services, with administrative headquarters in Italy. ${ }^{4}$ The survey adopts a one-stage stratified sample design. The strata are combinations of branch of activity (according to an 11-sector classification), size class (in terms of number of employees classified in 7 buckets), and region in which the firm's head office is located. In recent years each wave has around 4,000 firms (3,000 industrial firms and 1,000 service firms).

The data are collected by the Bank of Italy's local branches between February and April every year. Among other things, the survey asks firms to report their sales, investment, and employment in three periods: the fiscal year that just ended (preliminary results), the previous fiscal year (final results), and the current fiscal year

\footnotetext{
${ }^{4} \mathrm{~A}$ methodological note about the survey can be found at https:/tinyurl.com/v6unt8n.
} 
(forecasts). Throughout the paper, we define firm i's empirical log-sales forecast errors as the difference between the log of firm $i$ 's actual sales and the log of firm $i$ 's sales forecast:

$$
\widehat{F E}_{i t}=\log \text { sales }_{i t}-\log F_{i, t-1} \text { sales }_{i t}
$$

where sales $_{i t}$ is total sales of year $t$ and $F_{i, t-1}$ sales $_{i t}$ is sales forecast reported in February to April of year $t$.

To compute the firm-specific log-sales forecast error, we measure actual sales ( sales $_{i t}$ ) using firm balance sheet data from Company Accounts Data System (CADS), which is managed by the Cerved Group and covers all Italian limited liability companies. We do not use the self-reported sales data in INVIND to measure actual sales (i.e. final result for previous fiscal year) as this information might be subject to self-reporting biases.

Our Italian survey-account sample runs from 2002 through 2017, and contains about 37,000 total firm-year observations. We keep firms that report at least 5 sales forecasts. We winsorize all variables at the median $+/-5$ times the interquartile range.

\section{Summary Statistics}

Table 1 provides summary statistics for our working sample. Panel A focuses on firms for which forecast data are available. Panel B provides descriptive statistics for the universe in order to make a comparison. Log-sales forecast errors as defined above have a mean of -.01. That the mean log-sales forecast is negative is expected as a result of Jensen's inequality. Log-sales forecast errors have a standard deviation of 18\%. Figure 1 reports a histogram of log-sales forecast error. This figure shows that the log-sales forecast error is close to normally distributed.

\subsection{Forecast Informativeness}

We now verify the informativeness of managerial sales forecasts in our data. One possible concern is that these reported forecasts are only weakly correlated with managers' true forecasts, for instance because managers put little effort in answering the survey. In Table 2, we show that sales forecasts are highly informative about actual future sales. To this end, we estimate the following simple linear regression:

$$
\frac{\text { sales }_{i t}}{\text { assets }_{i, t-1}}=\alpha+\beta \frac{F_{i, t-1} \text { sales }_{i t}}{\text { assets }_{i, t-1}}+\epsilon_{i t},
$$

where sales $_{i t}$ and $F_{i, t-1}$ sales $_{i t}$ represent respectively firm $i$ 's actual and forecasted sales as defined above and $a_{s s e t} s_{i, t-1}$ denotes firm $i$ 's value of assets at the end of period 
$t-1$. Standard errors are clustered by both firm and time. Table 2, column (1) shows that the coefficient estimate for $\beta$ is .97 with a standard error of .007 . The $R^{2}$ of this regression is $90 \%$ without any fixed effect. Column (2) to (6) augment this regression by successively adding control variables (beginning-of-year log assets and

log sales), year fixed-effect, industry fixed-effect, industry-year fixed-effect, firm and year fixed-effects. These specifications are consistent with the finding in Column (1) that managerial forecasts reported in the survey data strongly forecasts future realized sales. In Column (7) to (10), we confirm these results using a slightly different specifications: we use the log of realized sales as our main dependent variable and regress it against the $\log$-sales forecast $\left(\log \left(F_{i, t-1}\right.\right.$ sales $\left.\left._{i t}\right)\right)$ and a host of control variables. These regressions show that our data on managerial forecasts have useful empirical content. However, they do not prove that the reported sales forecasts are free of measurement error. As a result, we will include in our model measurement error in reported sales forecast. We will identify such measurement error through a combination of two moments: the variance of sales forecast errors and the relationship between sales forecasts and capital investment decisions.

\subsection{Forecasts and Capital Investment}

We now show that sales expectations are linked to firms' capital investment decisions at the time they are formed. To this end, we regress the log of firm i capital stock for fiscal year $t$ on log-sales forecasts issued at the beginning of year $t$ :

$$
\log k_{i t}=\alpha_{i}+\delta_{t}+\kappa_{\log (k) / \log (\mathbb{F})} \log F_{i, t-1} \text { sales }_{i t}+\epsilon_{i t}
$$

where $k_{i t}$ is measured as the capital stock (net fixed tangible assets) at the end of year $t-1$ : when there is a one period time to build, this is the capital stock that is used in production in year $t . F_{i, t-1}$ sales $_{i t}$ is the forecast of sales in year $t$ made at the beginning of the year and $\alpha_{i}$ and $\delta_{t}$ denote respectively firm and year fixed effects. Table 3 reports estimates of the coefficient $\kappa_{\log (k) / \log (\mathbb{F})}$ using manufacturing firms only (see Column (1)) and all firms in the sample (see Column (2)). In both cases, the estimated elasticity is statistically significant and about equal to .4: within a firm, a $10 \%$ increase in sales forecasts is associated with a $4 \%$ increase in the capital stock. As explained below, in a simple model with Cobb-Douglas production, noiseless forecasts and no capital friction, this elasticity turns out to be 1. Our Italian data suggest however a smaller response of investment to changes in sales forecasts than the benchmark frictionless model. This is why our model will feature both a real 
friction (adjustment cost in capital accumulation) and a measurement friction (noise in reported forecasts) to accommodate this empirical finding.

\subsection{Persistence of Forecast Errors}

Under rational expectations, managerial forecast errors should not be predictable using variables in the manager's information set, which presumably includes past sales and past forecasts. We document instead that managerial forecasts errors are persistent, and positively predictable by previous forecast errors. As hinted in the Introduction, this feature is consistent with underreaction to new information.

Figure 2 provides a binned scatter plot of the relationship between past log-sales forecast errors (defined as $\widehat{F E}_{i t-1}$ above) and current log-sales forecast errors ( $\left.\widehat{F E}_{i t}\right)$. To construct this figure, we split the sample in vigintiles of lagged log-sales forecast error (x-axis) and represent, on the y-axis, the average current log-sales forecast error. As shown, the relationship between lagged and current log-sales forecast error is increasing and close to linear.

We confirm this finding by estimating the following model:

$$
\widehat{F E}_{i t}=\alpha+\delta_{t}+\kappa_{F E} \widehat{F E}_{i, t-1}+\epsilon_{i t},
$$

where $\delta_{t}$ denotes year fixed effects and $\alpha$ is just a constant. Standard errors are clustered at the firm and year level.

Table 4 reports the estimates of coefficient $\kappa_{F E}$. Column (1) uses only manufacturing firms and finds an estimate of $\kappa_{F E}$ of .29. Column (3) uses all firms in the sample and reports an estimated $\kappa_{F E}$ of .32. In both cases, the estimated $\kappa_{F E}$ is highly significant. Columns (2) and (4) add firm fixed effects to equation (1) for manufacturing and all firms respectively. These fixed effects allow firms to exhibit an average bias in their forecast over the sample period (either over-optimism or over-pessimism). It is obviously challenging to disentangle the persistence of forecast errors from a firm-specific constant since our panel dataset contains a finite time length (at most 16 years). In particular, this augmented model cannot be estimated consistently using OLS given the short time period in our sample (Nickell (1981)). As a result, we further restrict the sample to firms with at least 9 forecasts and estimate the model using dynamic panel GMM (Arellano and Bover (1995)). This augmented model leads to an estimate of $\kappa_{F E}$ of .17 for all firms (.159 for manufacturing), significant at the $1 \%$ level.

The results in Table 4 are consistent with the hypothesis that managers underreact to sales-related news. A positive news at date $t$ about date $t$ sales (e.g., a positive 
productivity shock) implies a positive forecast error at date $t$. If productivity is persistent, and the manager is slow to incorporate this news into her forecast for date $t+1$ sales, then this manager is too pessimistic at date $t$ about date $t+1$ sales, which leads her to exhibit, on average, a positive forecast error at date $t+1$. Hence, the positive autocorrelation of forecast errors is consistent with underreaction.

A possible concern about the relevance of the finding in Table 4 is that the persistence in forecast error is mostly a phenomenon among small firms. We split the entire sample of firms into 5 size groups based on the firm's number of employees. For each of these groups, we re-run regression (1) separately, both with and without firm fixed effects. We report results in Table 5. Across size groups, the point estimate for $\kappa_{F E}$ is strongly significant and ranges from .28 to .42 without firm fixed effects and between .143 and .211 when including firm fixed effects. A similar pattern emerges for manufacturing firms as seen in column (3) and (4). If anything, the persistence in forecast errors seems to be slightly increasing with firm size, although given the confidence intervals, we cannot reject the null hypothesis that the estimated autoregressive coefficients are constant across size groups. As a result, we feel comfortable assuming that firms are homogeneous in terms of $\kappa_{F E}$ in our quantitative exercise.

Taken together, the results in Table 4 and Table 5 reject the null hypothesis that managers process information efficiently. However, we cannot directly interpret these point estimates from an economic standpoint. What do they imply for the firm's investment policy and firm value? To answer this question one would need a structural model in order to "shut down" the forecasting biases that we observe in the data and construct appropriate counterfactuals. This is what we do in Section 3.

\section{Structural Model}

\subsection{Model Setup}

We start from a standard neoclassical model of investment augmented with two types of frictions: (1) real capital frictions (one-period time-to-build and quadratic adjustment costs), and (2) distorted beliefs.

\subsubsection{Economy}

Time is discrete. At date $t$, firm $i$ combines capital $\left(k_{i t}\right)$ and labor $\left(l_{i t}\right)$ to generate sales $\left(p_{i t} y_{i t}\right)$ with a Cobb-Douglas technology: 


$$
p_{i t} y_{i t}=A e^{\nu_{i t}}\left(k_{i t}^{\alpha} l_{i t}^{1-\alpha}\right)^{\theta},
$$

where $\nu_{i t}$ is revenue-based log-productivity, $\alpha$ is the capital share, and $\theta$ captures decreasing returns to scale in revenues, which may arise from technology or market power. $A$ is a positive constant. Input markets are competitive. $w$ is the wage rate in the labor market and $r$ is the safe rate of return in this economy. ${ }^{5}$ At date $t$, firms hire $l_{i t}$ employees after observing $\nu_{i t}$. We assume an AR(1) process for $\nu_{i t}$ :

$\nu_{i t}=(1-\rho) \mathcal{V}_{i}+\rho \nu_{i t-1}+\psi_{i t}+\omega_{i t}$ with $\left(\omega_{i t}, \psi_{i t}\right) \sim \mathcal{N}\left[\left(\begin{array}{l}0 \\ 0\end{array}\right),\left(\begin{array}{lr}\sigma_{\omega}^{2} & 0 \\ 0 & \sigma_{\psi}^{2}\end{array}\right)\right] \& \mathcal{V}_{i} \sim \mathcal{N}\left(0, \sigma_{\mathcal{V}}^{2}\right)$

where $\mathcal{V}_{i}$ is the long-run mean of firm $i$ 's productivity. Furthermore, $\omega_{i t}$ is a shock realized at date $t$ whereas $\psi_{i t}$ denotes a private signal observed by the manager at date $t-1$ (but not by the econometrician). Our model thus allows for managerial private information about future productivity, as in David and Venkateswaran (2019).

At date $t$, the firm chooses labor demand $l_{i t}$, given current productivity $\nu_{i t}$ and installed capital $k_{i t}$, to maximize operating profits:

$$
\max _{l_{i t}}\left\{A e^{\nu_{i t}} k_{i t}^{\alpha \theta} l_{i t}^{(1-\alpha) \theta}-w l_{i t}\right\}=\Omega e^{\frac{\Phi}{\alpha \theta} \nu_{i t}} k_{i t}^{\Phi}
$$

where $\Phi \equiv \frac{\alpha \theta}{1-(1-\alpha) \theta}$ and $\Omega \equiv(1-(1-\alpha) \theta)\left(\frac{(1-\alpha) \theta}{w}\right)^{\frac{1-\alpha}{\alpha} \Phi} A^{\frac{\Phi}{\alpha \theta}}$.

We assume a one-period time-to-build in capital: firms invest in the capital stock $k_{i t}$ before $\nu_{i t}$ is realized. As a result, before investing managers need to form expectations about next-period productivity. The next section describes our model of belief formation.

\subsubsection{Distorted Expectations}

Managers may exhibit distorted expectations about future productivity. In the spirit of Bordalo et al. (2017), we assume that managers use the following conditional density:

$$
h_{t-1}^{s}\left(\nu_{i t} \mid \nu_{i t-1}, \psi_{i t}\right)=h\left(\nu_{i t} \mid \nu_{i t-1}, \psi_{i t}\right)\left[\frac{h\left(\nu_{i t} \mid \nu_{i t-1}, \psi_{i t}\right)}{h\left(\nu_{i t} \mid \widehat{\nu_{i t-1}}=\rho \nu_{i t-2}+\psi_{i t-1}, \psi_{i t}\right)}\right]^{\gamma} \frac{1}{Z}
$$

\footnotetext{
${ }^{5}$ We omit the time subscript for $w$ and $r$, as we only consider steady-state economies.
} 
where $Z$ is a normalization coefficient. The subjective density $h^{s}$ depends on two terms. The first term, $h$, is the objective conditional distribution of $\nu_{i t}$, conditional on the information available at the beginning of date $t, \nu_{i t-1}$ and $\psi_{i t}$. The second term corresponds to the over- or underreaction to the surprise realization $\omega_{i t-1}$. The "diagnosticity" is large when the past realization of productivity is high compared to its rational expectation. Those states are overweighted when $\gamma>0$ (representativeness bias in Bordalo et al. (2017)). They are underweighted when $\gamma<0$. A negative $\gamma$ can be rationalized as a lack of attention: large surprises are less representative of potential realization and therefore more likely to be overlooked. From a psychological standpoint, such a bias can be related to the "conservatism" bias emphasized in Edwards (1968).

Given our parametric assumptions on the distribution of $\omega$ and $\psi$, it is straightforward to show that the formulation of beliefs in Equation (4) leads the manager to believe in the following conditional distribution for $\nu_{i t}$ :

$$
\nu_{i t} \sim \mathcal{N}((1-\rho) \mathcal{V}_{i}+\rho \nu_{i t-1}+\psi_{i t}+\underbrace{\gamma \rho \omega_{i t-1}}_{\text {over/underreaction }}, \sigma_{\omega}^{2})
$$

Note that when $\gamma=0$, this formulation boils down to the rational expectation. When $\gamma>0$ (resp. $<0$ ), managers overreact (resp. underreact) to the date $t-1$ innovation in productivity $\omega_{i t-1}$. This formulation is similar to Bordalo et al. (2017), but extends it to underreaction by allowing $\gamma$ to be negative, which will turn out to be the case in our estimation.

The final feature of reported managerial forecasts in our model is that they may contain noise. Such noise can help explaining the low elasticity of capital to managerial forecast we document in Table 3, and is a reasonable assumption when dealing with survey data (Giglio et al., 2019). More precisely, we assume that reported logsales forecasts are described by:

$$
\log \left(\widehat{\mathbb{F}_{i, t-1}}\left[p_{i t} y_{i t}\right]\right)=\log \left(\mathbb{F}_{i, t-1}\left[p_{i t} y_{i t}\right]\right)+\zeta_{i t}, \quad \text { where: } \zeta_{i t} \sim \mathcal{N}\left(0, \sigma_{\zeta}^{2}\right)
$$

where $\log \left(\widehat{\mathbb{F}_{i, t-1}}\left[p_{i t} y_{i t}\right]\right)$ is the observed sales forecast and $\log \left(\mathbb{F}_{i, t-1}\left[p_{i t} y_{i t}\right]\right)$ is the true forecast on which the manager bases her investment decisions.

Sales forecasts are not structural objects but depend on endogenous employment decisions by managers. We assume that there is a one-period time to build in capital so that sales forecasts take the capital decision as given. But labor is expected to be ex-post chosen optimally. With the formulation of forecasts in Equation (5), the 
empirical log-sales forecast error $\left(\widehat{F E}_{i t}\right)$ then admits a simple expression:

$$
\begin{aligned}
\widehat{F E}_{i t} & =\log \left(p_{i t} y_{i t}\right)-\log \left(\mathbb{F}_{t-1}\left[p_{i t} y_{i t}\right]\right)-\zeta_{i t} \\
& =\underbrace{-\frac{\Phi}{\alpha \theta} \gamma \rho \omega_{i t-1}}_{\text {Belief distortions }}+\underbrace{\frac{\Phi}{\alpha \theta} \omega_{i t}-\frac{1}{2}\left(\frac{\Phi}{\alpha \theta}\right)^{2} \sigma_{\omega}^{2}}_{\text {Rational expectation error }}-\underbrace{\zeta_{i t}}_{\text {Noise }}
\end{aligned}
$$

Log-sales forecast errors are first driven by the bias parameter $\gamma$. Past positive productivity shocks will lead to larger future forecast errors if $\gamma<0$. This will induce persistence in forecast errors, as we find in the data. The rational expectation error is negative on average, due to Jensen's inequality. Forecast errors also include the expectation noise $\zeta_{i t}$. However, private information is not part of forecast errors, as should be expected. This will help identification as we discuss below.

\subsubsection{Investment}

Capital $k_{i t}$ is selected at $t-1$ and depreciates at the constant rate $\delta$. When investing, we assume that the firm faces quadratic adjustment cost to capital (Hayashi, 1982). Specifically, starting from capital $k_{i t-1}$, installing capital $k_{i t}$ costs the firm $c_{k} \frac{\left(k_{i t}-(1-\delta) k_{i t-1}\right)^{2}}{k_{i t-1}}$, in addition to the actual capital expenditures. As discussed above, in addition to the measurement error on sales forecast, this feature of the model is useful to rationalize the low elasticity of capital to sales forecast observed in the data (Table 3).

These adjustment costs imply that the firm's manager faces a dynamic optimization problem. This problem can be represented by a Bellman equation with four state variables. The endogenous state variable is the capital stock installed in the previous period, $k$. The three exogenous state variables are (1) the current level of productivity $\nu$, (2) the private information about next period productivity $\psi$, and (3) the current shock $\omega$. In particular, $\omega$ is a state variable because the manager bases her forecast on the subjective distribution described in Equation (5), so that she does not process the news about $\omega$ efficiently. ${ }^{6}$

Since we consider a steady-state economy with no aggregate risk, the firm discounts future profits at the safe rate of return. As a result, for a firm with long term productivity $\mathcal{V}_{i}$, the dynamic optimization problem admits the following Bellman rep-

\footnotetext{
${ }^{6}$ For a rational manager, at date $t, \nu_{i t}$ and $\psi_{i t+1}$ are sufficient to make an efficient forecast about $\nu_{i t+1}$.
} 
resentation:

$$
\begin{aligned}
V^{i}\left(k_{i t} ;\left(\nu_{i t}, \omega_{i t}, \psi_{i t+1}\right)\right)=\max _{k_{i t+1}}\{ & \Omega e^{\frac{\Phi}{\alpha \theta} \nu_{i t}} k_{i t}^{\phi}-\left(k_{i t+1}-(1-\delta) k_{i t}\right)-c_{k} \frac{\left(k_{i t+1}-(1-\delta) k_{i t}\right)^{2}}{k_{i t}} \\
& \left.+\frac{1}{1+r} \mathbb{F}_{i t}\left[V^{i}\left(k_{i t+1} ; \nu_{i t+1}, \omega_{i t+1}, \psi_{i t+2}\right) \mid\left(\nu_{i t}, \omega_{i t}, \psi_{i t+1}\right)\right]\right\}
\end{aligned}
$$

with:

$$
\left(\begin{array}{c}
\nu_{i t+1} \\
\omega_{i t+1}
\end{array}\right) \stackrel{\mathbb{F}}{\sim} \mathcal{N}\left(\left(\begin{array}{c}
(1-\rho) \mathcal{V}_{i}+\rho \nu_{i t}+\gamma \rho \omega_{i t}+\psi_{i t+1} \\
0
\end{array}\right),\left(\begin{array}{cc}
\sigma_{\omega}^{2} & \sigma_{\omega}^{2} \\
\sigma_{\omega}^{2} & \sigma_{\omega}^{2}
\end{array}\right)\right) \text { and } \psi_{i t+2} \stackrel{\mathbb{F}}{\sim} \mathcal{N}\left(0, \sigma_{\psi}^{2}\right)
$$

As shown formally in Appendix A.1, we can simplify the previous problem by expressing its solution as a function of another Bellman equation that does not depend on long-term productivity. Consider the following Bellman equation:

$$
\begin{aligned}
V\left(k_{i t} ;\left(\nu_{i t}, \omega_{i t}, \psi_{i t+1}\right)\right)=\max _{k_{i t+1}}\{ & \Omega e^{\frac{\Phi}{\alpha \theta} \nu_{i t}} k_{i t}^{\phi}-\left(k_{i t+1}-(1-\delta) k_{i t}\right)-c_{k} \frac{\left(k_{i t+1}-(1-\delta) k_{i t}\right)^{2}}{k_{i t}} \\
& \left.+\frac{1}{1+r} \mathbb{F}_{i t}\left[V\left(k_{i t+1} ; \nu_{i t+1}, \omega_{i t+1}, \psi_{i t+2}\right) \mid\left(\nu_{i t}, \omega_{i t}, \psi_{i t+1}\right)\right]\right\}
\end{aligned}
$$

with:

$$
\left(\begin{array}{c}
\nu_{i t+1} \\
\omega_{i t+1}
\end{array}\right) \stackrel{\mathbb{F}}{\sim} \mathcal{N}\left(\left(\begin{array}{c}
\rho \nu_{i t}+\gamma \rho \omega_{i t}+\psi_{i t+1} \\
0
\end{array}\right),\left(\begin{array}{cc}
\sigma_{\omega}^{2} & \sigma_{\omega}^{2} \\
\sigma_{\omega}^{2} & \sigma_{\omega}^{2}
\end{array}\right)\right) \text { and } \psi_{i t+2} \stackrel{\mathbb{P}}{\sim} \mathcal{N}\left(0, \sigma_{\psi}^{2}\right)
$$

Then, let $k^{*}\left(k_{i t} ;\left(\nu_{i t}, \omega_{i t}, \psi_{i t+1}\right)\right)$ be the optimal policy function of this Bellman problem and let $V\left(k_{i t} ;\left(\nu_{i t}, \omega_{i t}, \psi_{i t+1}\right)\right)$ be its optimal value. It is straightforward to show that the optimal policy function $k^{i, *}\left(k_{i t} ;\left(\nu_{i t}, \omega_{i t}, \psi_{i t+1}\right)\right)$ and the value function $V^{i}\left(k_{i t} ;\left(\nu_{i t}, \omega_{i t}, \psi_{i t+1}\right)\right)$ of a firm with long-term productivity $\mathcal{V}_{i}$ can be expressed as:

$$
\left\{\begin{array}{l}
k^{i, *}\left(k_{i t} ;\left(\nu_{i t}, \omega_{i t}, \psi_{i t+1}\right)=e^{\frac{\nu_{i}}{1-\theta}} \times k^{*}\left(\frac{k_{i t}}{\left.e^{\frac{\nu_{i}}{1-\theta}} ;\left(\nu_{i t}-\mathcal{V}_{i}, \omega_{i t}, \psi_{i t+1}\right)\right)}\right.\right. \\
V^{i}\left(k_{i t} ;\left(\nu_{i t}, \omega_{i t}, \psi_{i t+1}\right)=e^{\frac{\nu_{i}}{1-\theta}} \times V\left(\frac{k_{i t}}{e^{\frac{\nu_{i}}{1-\theta}}} ;\left(k_{i t} ;\left(\nu_{i t}-\mathcal{V}_{i}, \omega_{i t}, \psi_{i t+1}\right)\right)\right.\right.
\end{array}\right.
$$

We can therefore solve the problem of a firm with long-term productivity $\mathcal{V}_{i}$ by simply solving the Bellman problem (8) and then applying Equation (9) to its value and policy function. 


\subsection{Model Identification}

In our baseline estimation, we calibrate four parameters: $\alpha$, the capital share, is calibrated to be $33 ; \theta$, the decreasing returns to scale in revenue, is $.8 ; \delta$, the depreciation rate of capital is set to $10 \%$; finally, the risk-free rate, $r$, is calibrated to $5 \%$. In Section 6 below, we show that our main findings are robust to alternative calibration of $\alpha$ and $\theta$.

We estimate the key parameters of the model via a Simulated Method of Moments (SMM). We look for the set of parameters $\Theta=\left(\rho, \sigma_{\omega}, \sigma_{\psi}, \gamma, \sigma_{\zeta}, c_{k}, \sigma_{\mathcal{V}}\right)$ such that modelgenerated moments $m(\Theta)$ on simulated data fit a predetermined set of data moments $\boldsymbol{m}$. We use indirect inference because we cannot solve the model analytically (but we solve a particular case analytically below in order to build intuition). Our SMM estimation is done in two steps:

1. For a given set of parameters, we solve the Bellman equation (8) numerically and obtain the optimal policy function $k^{i, *}$. We use policy function iteration on a discrete grid for the state space $(k ;(\nu, \omega, \psi))$

2. Our parameter estimates minimize the distance from simulated to data moments,

$$
\hat{\boldsymbol{\Theta}}=\operatorname{argmin}_{\Theta}\left((\boldsymbol{m}-m(\Theta))^{\prime} \Sigma(\boldsymbol{m}-m(\Theta))\right)
$$

where the weighting matrix $\Sigma$ is the inverse of the variance-covariance matrix of empirical moments. Standard errors are obtained by bootstrapping on the estimation sample using a block bootstrap at the firm-level.

We now describe the set of moments we use in our estimation. We follow David et al. (2016) and construct revenue-based productivity using our calibration for $\alpha$ and $\theta$. For firm $i$ at date $t$, we compute its productivity as $\left.\hat{\nu}_{i t}=\frac{\alpha \theta}{\Phi}\left(\log \left(V A_{i t}\right)-\Phi \log \left(k_{i t}\right)\right)\right)$, where $V A_{i t}$ denotes firm $i$ 's value added for fiscal year $t^{7}$ and $k_{i t}$ is the stock of net fixed tangible assets at the end of year $t-1 .{ }^{8}$ Both variables are taken from CADS.

We then estimate three moments that capture the dynamic process followed by firms' productivity as posited in Equation (2). The first moment is $\widehat{\chi}=\frac{\operatorname{Var}\left(\hat{\nu}_{i t}-\hat{\nu}_{i t-2}\right)}{\operatorname{Var}\left(\hat{\nu}_{i t}-\hat{\nu}_{i t-1}\right)}-1$. If $\hat{\nu}_{i t}$ follows an $\operatorname{AR}(1)$ process with a persistent component, then $\hat{\chi}$ is an unbiased

\footnotetext{
${ }^{7}$ Note that our model does not have intermediary inputs, so that value added is equal to total sales. The model can be extended to include intermediary inputs by assuming a Cobb-Douglas production function in inputs, labor and capital. Value added is then simply a constant share of total sales and all our analysis carries through.

${ }^{8}$ In the model, $k_{i t}$ is determined at date $t-1$ but can only be used for production in period $t$. PPE observed in year $t-1$ includes the capital expenditures made in year $t-1$ and thus corresponds to our definition of $k_{i t}$ in the model.
} 
estimate of $\rho$ in the model, even in small sample (Lo and MacKinlay (1988)). We then compute $\mathbb{V}_{i}=\frac{1}{T} \sum_{t=1}^{T} \frac{\hat{\nu}_{i t}-\widehat{\chi} \hat{\nu}_{i t-1}}{1-\hat{\chi}}$ and then estimate its cross-sectional variance: $\sigma_{V}^{2}=\operatorname{Var}_{i}\left(\mathbb{V}_{i}\right)$. In the model, $\mathbb{V}_{i}$ depends on the long-term productivity of firm $i, \mathcal{V}_{i}$ and the within-firm average of TFP innovations: $\mathbb{V}_{i}=\left(\mathcal{V}_{i}+\frac{1}{T} \sum_{t=1}^{T} \frac{\left(\omega_{i t}+\psi_{i t}\right)}{1-\rho}\right)$. Finally, we estimate the variance of TFP residuals $\widehat{\sigma}_{\tau}^{2}=\operatorname{Var}\left(\hat{\nu}_{i t}-\hat{\chi} \hat{\nu}_{i t-1}-(1-\hat{\chi}) \mathbb{V}_{i}\right)$, which provides an estimate of the variance of innovations to the productivity process $\left(\sigma_{\psi}^{2}+\sigma_{\omega}^{2}\right.$ in the model).

More specifically, our estimation targets the following seven empirical moments, which include the three moments pertaining to firms' productivity process just described as well as four additional moments relating to managerial forecasts and investment:

1. Variance of the estimated productivity innovations $\widehat{\sigma}_{\tau}^{2}$. This estimate has a direct counterpart in the model: $\widehat{\sigma}_{\tau}^{2}=\sigma_{\omega}^{2}+\sigma_{\psi}^{2}$, a combination of the true innovation in the TFP process and the information about TFP innovations privately known by the manager a period in advance.

2. Estimated persistence of productivity process $\widehat{\chi}$. In the model, this estimate corresponds directly to the persistence parameter $\rho$ in Equation (2).

3. The cross-sectional variance of $\mathbb{V}_{i}$ : as explained above, $\mathbb{V}_{i}$ corresponds in the model to the persistent component in TFP $\mathcal{V}_{i}$, plus the within-firm average of TFP innovations $\left.\frac{1}{T} \sum_{t=1}^{T} \frac{\left(\omega_{i t}+\psi_{i t}\right)}{1-\rho}\right)$. We target the cross-sectional variance of $\mathbb{V}_{i}$ : $\sigma_{V}^{2}=\operatorname{Var}_{i}\left(\mathbb{V}_{i}\right)$.

4. Persistence of sales forecast errors. Given the closed-form expression for logsales forecast error in Equation (7), it is possible to show that (see Appendix A.2):

$$
\kappa_{F E}=-\frac{\left(\frac{\Phi}{\alpha \theta}\right)^{2} \gamma \rho \sigma_{\omega}^{2}}{\sigma_{F E}^{2}}
$$

where $\sigma_{F E}^{2}$ is the variance of log-sales forecast errors.

As discussed in the empirical Section, Table 4 presents the empirical estimates for $\kappa_{F E}$. We use Columns (1) and (3). These specifications do not include firm fixed-effects, since our model does not allow for systematic optimism/pessimism bias. Intuitively, this moment helps identify the structural parameter $\gamma$, which governs the degree of over- or underreaction. Under rational expectations ( $\gamma=$ 0 ), forecast errors should be i.i.d. over time and $\kappa_{F E}$ should be 0 . As explained 
in Section 2.4, persistent forecast errors $\left(\kappa_{F E}>0\right)$ are consistent with underreaction $(\gamma<0)$.

5. Variance of log-sales forecast errors (net of year fixed effects) $\left(\widehat{\sigma F E}^{2}\right)$. In Appendix A.2, we show that this variance can be derived from Equation (7):

$$
\sigma_{F E}^{2}=\sigma_{\zeta}^{2}+\left(\frac{\Phi}{\alpha \theta}\right)^{2}\left(1+\gamma^{2} \rho^{2}\right) \sigma_{\omega}^{2}
$$

The variance of forecast errors contains the rational forecast error, $\left(\frac{\Phi}{\alpha \theta}\right)^{2} \sigma_{\omega}^{2}$, and two extra terms: the expectation noise $\sigma_{\zeta}^{2}$ and the additional effect of forecasting biases $\left(\frac{\Phi}{\alpha \theta}\right)^{2} \gamma^{2} \rho^{2} \sigma_{\omega}^{2}$. As usual in expectations studies, expectations biases increase the variance of forecast errors whether biases consist of over- or underreaction, since the rational expectation is the minimum MSE estimate.

6. Autocorrelation of firm investment rate, $\widehat{\kappa_{\text {capex }}}$. In the data we estimate this coefficient through a simple linear model (with time fixed-effects):

$$
\frac{k_{i t+1}-(1-\delta) k_{i t}}{k_{i t}}=\alpha+\kappa_{\text {capex }} \frac{k_{i t}-(1-\delta) k_{i t-1}}{k_{i t-1}}+\epsilon_{i t}
$$

Intuitively, $\kappa_{\text {capex }}$ captures the extent of quadratic adjustment $\operatorname{costs} c_{k}$, and is a moment classically used to pin down capital adjustment cost (e.g. Cooper and Haltiwanger (2006)).

7. Elasticity of the capital stock to sales forecast. As explained above, in a frictionless model with Cobb-Douglas production function, this elasticity should be one, whether expectations are rational or not. Intuitively, this elasticity will be lower than one in the presence of capital adjustment costs $\left(c_{k}\right)$ and the variance of noise in the sales forecast $\left(\sigma_{\zeta}^{2}\right)$. We do not have a closed form solution for this moment to match with the estimates reported in Table 3 , but we build intuition with a model without adjustment costs in the next Section.

To illustrate how the model is identified, Figure 3 shows numerical comparative statics for the estimated model. To construct this figure, we start from the set of parameters estimated in Section 3.4 below. We then vary one of the parameters around its estimated value and re-compute the simulated moments with this alternative set of parameters. Figure 3 reports the parameter/moment pairs for which a variation in the parameter leads to a significant variation in the simulated moment. Figure 3 highlights a number of intuitive relationships in the data. Adjustment $\operatorname{costs} c_{k}$ 
increase the persistence of investment and decrease the elasticity of capital to forecast. The noise in managerial forecasts, $\sigma_{\zeta}$, increases the variance of forecast errors, but decrease the persistence of forecast errors and the elasticity of capital to forecast (attenuation bias). A more persistent TFP process $(\rho$ ) leads to a higher estimated persistence of TFP residuals $\hat{\chi}$, but also to a larger variance of forecast errors, a larger persistence of forecast errors, a larger persistence of investment and a larger elasticity of capital to forecast. An increase in inattention, i.e., a lower $\gamma$, mostly leads to an increase in the variance of forecast errors, and an increase in the persistence of forecast errors. An increase in the dispersion of the true TFP innovations, $\sigma_{\omega}$, leads to an increase in the variance of forecast errors, an increase in the persistence of forecast errors, an increase in the variance of total TFP innovations $\left(\sigma_{\tau}^{2}\right)$, an increase in the cross-sectional variance of $\mathbb{V}_{i}$, and an increase in both the persistence of investment and the elasticity of capital to forecasts. Symmetrically, an increase in the private information component of TFP innovations, $\sigma_{\psi}$, leads to a decrease in both the persistence of investment and the elasticity of capital to forecasts. Identification in our model is obtained through the combination of these relationships between simulated moments and structural parameters. In the next section, we build further intuitions by considering a simplified version of our model.

\subsection{Building Intuition}

In this section, we build a number of intuitions for the estimation by exploring a simpler version of the model that features no adjustment costs to capital $\left(c_{k}=0\right)$ and no measurement error in reported sales forecast $\left(\sigma_{\zeta}=0\right)$.

In this simplified version of the model, the optimal capital stock admits a closedform solution. In the absence of adjustment costs, the user cost of capital is $R=r+\delta$, and the firm selects its optimal capital stock at date $t-1$ to maximize date $t$ profits, that is:

$$
\max _{k_{i t}}\left\{\Omega \mathbb{F}_{i t-1}\left[e^{\frac{\Phi}{\alpha \theta} \nu_{i t}}\right] k_{i t}^{\Phi}-R k_{i t}\right\}
$$

which then yields

$$
k_{i t}=\left(\frac{\Phi}{R}\right)^{\frac{1}{1-\Phi}} \Omega^{\frac{1}{1-\Phi}}\left(\mathbb{F}_{i t-1}\left[e^{\frac{\Phi}{\alpha \theta} \nu_{i t}}\right]\right)^{\frac{1}{1-\Phi}}
$$

Using our formula for distorted expectations, it is straightforward to show that 
the optimal log-capital stock is:

$\log \left(k_{i t}\right)=\frac{1}{1-\Phi}\left(\log \left(\frac{\Phi \Omega}{R}\right)+\frac{\Phi}{\alpha \theta}\left((1-\rho) \mathcal{V}_{i}+\rho\left(\nu_{i t-1}+\gamma \omega_{i t-1}\right)+(1+\lambda) \psi_{i t}\right)+\frac{1}{2}\left(\frac{\Phi}{\alpha \theta}\right)^{2} \sigma_{\omega}^{2}\right)$

In particular, in this simple model, the first-order condition in capital implies a unit elasticity of capital to forecast:

$$
\log \left(k_{i t}\right)=\log \left(\frac{\Phi \Omega}{R}\right)+\log \left(\mathbb{F}_{t-1}\left[p_{i t} y_{i t}\right]\right)
$$

This model is obviously unable to account for the finding in Table 3: in the data, this elasticity is around .4. The data thus calls for an additional ingredient to break this unit elasticity. The first ingredient we consider is measurement error in the reported forecast: $\log \left(\widehat{\mathbb{F}_{i, t-1}}\left[p_{i t} y_{i t}\right]\right)=\log \left(\mathbb{F}_{i, t-1}\left[p_{i t} y_{i t}\right]\right)+\zeta_{i t}$, where $\zeta_{i t} \sim \mathcal{N}\left(0, \sigma_{\zeta}^{2}\right)$. The noise term $\zeta$ serves as classical measurement error for the log-sales forecast and therefore biases downwards the coefficient of a regression of $\log \left(k_{i t}\right)$ on $\log \left(\mathbb{F}_{t-1}\left[p_{i t} y_{i t}\right]\right)$.

However, having measurement error only is unlikely to fully account for the low elasticity in Table 3. In the data, the variance of $\log \left(\mathbb{F}_{t-1}\left[p_{i t} y_{i t}\right]\right)$ net of firm and year fixed-effects ${ }^{9}$ is about .083 . As a result, measurement error as specified above would induce a downward bias of about $\frac{\sigma_{\zeta}^{2}}{.083}$. On the other hand, we also know that measurement errors are bounded by the variance of forecast errors, which is .03. Therefore, even if managers had perfect foresight and forecast errors only came from noise, the resulting downward bias would lead to an elasticity of $\approx 1-\frac{.03}{.083} \approx .64$, which is still much larger than the elasticity in the data. This result explains why we also introduce quadratic adjustment costs to capital as another mechanism to lower the response of capital to sales forecasts.

\subsection{Model Estimation}

Table 6 reports the results of our structural estimation. Panel A shows the estimation results using only firms in manufacturing. Panel B shows the estimation results using all firms in the sample. Each panel reports the parameter estimates, as well as the empirical moments and their model counterparts.

We first discuss the parameter estimates. Since the results across the two samples are similar, we focus our discussion on Panel B, which uses all firms in the sample.

\footnotetext{
${ }^{9}$ For obvious identification reasons, we include firm and year fixed-effects in the regressions in Table 3
} 
We estimate $\gamma$ at -.56. This coefficient estimate implies significant underreaction to the realization of productivity innovation $\omega_{i t}$ when forecasting date $t+1$ productivity. A rational manager's date $t$ forecast for date $t+1$ productivity is: $(1-\rho) \mathcal{V}_{i}+\rho \nu_{i t}+\psi_{i t-1}$. In the model, the manager instead forecasts $(1-\rho) \mathcal{V}_{i}+\rho\left(\nu_{i t}+\gamma \omega_{i t}\right)+\psi_{i t-1}$. A $\gamma$ of -.56 implies a weight of $\omega_{i t}$ in date $t$ forecast of about half that of a rational manager.

We also find that $\omega$ and $\psi$ have approximately the same volatility (respectively $7.4 \%$ and $8.7 \%$ ). In other words, about half of the variance of observed productivity innovations is driven by managerial private information $(\psi)$. The remaining half comes from the true innovation $\omega$. Overall, however, both shocks are relatively small: this is because the variance of TFP innovations in the data is itself limited ( $\sigma_{\tau}^{2}=.013$ ). This low volatility of $\omega$ limits the potential of mistakes due to forecasting biases. In the data, the variance of log-sales forecast errors is .03 . The variance of log-sales forecast errors due to underreaction is $\left(\frac{\Phi}{\alpha \theta}\right)^{2} \gamma^{2} \rho^{2} \sigma_{\omega}^{2} \approx .0036$ and therefore only accounts for about $12 \%$ of the total variance of $\log$-sales forecast errors. Our estimation also reveals limited noise in the managerial sales forecast: in our estimation, $\sigma_{\zeta}$ accounts only for $3 \%$ of the overall variance of log-sales forecast error. Overall, the variance of the rational forecast error represents about $85 \%$ of the total variance of log-sales forecast error.

Finally, the estimation uncovers significant adjustment costs to capital: $c_{k} \approx .35$. Relative to Cooper and Haltiwanger (2006), our estimate is larger: in their specification with only quadratic adjustment costs, they estimate a $c_{k}$ of about .22 (see Table 4 in Cooper and Haltiwanger (2006), where their $\gamma$ parameter corresponds to $2 \times c_{k}$ ). However, Cooper and Haltiwanger (2006) work with plant-level data, which typically exhibit a lower persistence of investment (in their dataset, the autocorrelation of investment at the plant-level is .058 relative to .483 in our sample). This is because investment at the plant level is lumpier.

Table 6 also compares the empirical moments targeted in the estimation with their model counterparts. The model manages to match all moments accurately except for the persistence of the productivity process: in the data, the persistence is estimated at .81 while the model needs a lower persistence of .68 to match all the other moments well. Apart from this persistence, the model can closely replicate three key moments of the data: (1) the persistence of log-sales forecast errors, which characterizes the degree of underreaction $\gamma$, (2) the variance of log-sales forecast errors, and (3) the relationship between changes in the capital stock and changes in sales forecast, which characterizes the link between observed forecasts in the data and real decisions by the firm. The model also matches closely the persistence in investment rates. 


\subsection{Partial equilibrium counterfactual}

In this section, we use our structural estimates to quantitatively compare average corporate behavior for firms with rational managers (i.e. assuming $\gamma=0$ ) relative to firms with managers that use distorted forecasts (i.e. assuming $\gamma=-.56$ ). To begin with, we do this in partial equilibrium, i.e. without clearing product and labor markets.

\section{Investment conditional on TFP shocks}

In Figure 4, we first consider the case of capital expenditures. We start by simulating a large dataset from the estimation obtained in Panel B of Table 6 (which uses the entire set of firms in the sample). We then simulate a second dataset with the same history of productivity shocks, but where managers are rational $(\gamma=0)$ instead of exhibiting underreaction. We then split each simulated sample into 20 vingitiles of productivity innovations $\left(\omega_{i t}\right)$ and report, for each of these bins, the average investment ratio $\left(\frac{k_{i t+1}-(1-\delta) k_{i t}}{k_{i t}}\right)$ for firms with rational managers (grey stars) and firms with non-rational managers (dark circles). The role of underreaction is evident in Figure 4: managers with distorted forecasts clearly underinvest when the productivity innovation $\omega_{i t}$ is large and overinvest when it is low. Quantitatively, this effect is sizeable. For a productivity shock at the 75th percentile of the distribution, the average manager in the data underinvest by $10.01 \%$ relative to a rational expectation counterfactual. Symmetrically, for a productivity shock at the 25 th percentile, the inattentive manager overinvests by $16.72 \%$ relative to a rational manager.

\section{Firm value conditional on TFP shocks}

While the distortions on investment policy observed in Figure 4 appear economically significant, we find smaller effect on firm value. Figure 5 repeats the exercise in Figure 4, but computes average firm value instead of average investment ratios. As expected, for a given productivity innovation $\omega_{i t}$, the value of a firm with rational forecasts is strictly larger than the value of a firm whose manager exhibits distorted forecasts. However, this difference is quantitatively limited: on average, the value of the rational firm is only $0.65 \%$ larger than the value of the firm with distorted forecasts. This finding remains similar whether or not we condition on the realized TFP innovation $\left(\omega_{i t}\right)$.

A natural interpretation is that, in our setting, firms select their capital stock to optimize their value without any additional constraints. As a result, at the optimum, 
first-order deviations in investment only have second-order effects on firm value. This finding remains, of course, a quantitative result: larger distortions in forecasts (i.e. a smaller $\gamma$ ) or more volatile productivity innovations (a larger $\sigma_{\omega}$ ) could well have resulted in large implications for firm value. However, given the estimated parameters, the effect is modest.

\section{Aggregation}

We nest the firm-level investment model of Section 3 into a general equilibrium framework. This allows us to explore the aggregate cost induced by managers' distorted forecasts.

\subsection{Aggregation Setup}

We consider a simple market structure following Dixit and Stiglitz (1977). There is a continuum of intermediate input producers: at date $t$, firm $i$ is a monopolist and produces quantity $y_{i t}$ of an intermediary input at price $p_{i t}$. These inputs are used in the production of a final good. The final good market is perfectly competitive, and aggregates intermediate inputs with a CES technology:

$$
Y_{t}=\left(\int_{i} y_{i t}^{\theta} d i\right)^{\frac{1}{\theta}}
$$

The price of the final good is normalized to 1. Profit maximization in the final good market implies that the demand for product $i$ is given by: $p_{i t}=\left(\frac{Y_{t}}{y_{i t}}\right)^{1-\theta}$, where $Y_{t}$ represents the aggregate level of output. There is a single labor market from which all firms hire workers at the wage rate $w_{t}$, which firms take as given. Households have GHH preferences over leisure and consumption: $u\left(c_{t}, l_{t}\right)=\left(c_{t}-\frac{w_{0}}{L_{0}^{\frac{1}{\epsilon}}} \frac{l_{t}^{1+\frac{1}{\epsilon}}}{1+\frac{1}{\epsilon}}\right)$. As a result, labor supply is $L_{0}\left(\frac{w_{t}}{w_{0}}\right)^{\epsilon}$ where $\epsilon$ is the constant labor supply elasticity.

The firm-level model of investment of Section 3 can be nested into this framework. Assume firm $i$ production combines labor and capital with a Cobb-Douglas technology: $y_{i t}=B e^{z_{i t}} k_{i t}^{\alpha} l_{i t}^{1-\alpha}$. Log-productivity $z_{i t}$ is stochastic and follows an AR(1) process:

$$
z_{i t}=\rho z_{i t-1}+\epsilon_{i t}+\eta_{i t} \text { with: }\left(\epsilon_{i t}, \eta_{i t}\right) \sim \mathcal{N}\left[\left(\begin{array}{l}
0 \\
0
\end{array}\right),\left(\begin{array}{cc}
\sigma_{\epsilon}^{2} & 0 \\
0 & \sigma_{\eta}^{2}
\end{array}\right)\right],
$$


where $\eta_{i t}$ is privately observed by the manager in period $t-1$. In particular, we assume no aggregate uncertainty so that aggregate output is constant $Y_{t}=Y$ and the equilibrium wage on the labor market is also constant $w_{t}=w$. Given that input producers are monopolists, profit maximization with respect to pricing decisions $\left(p_{i t}\right)$ implies that firms' revenue exhibit decreasing returns to scale:

$$
p_{i t} y_{i t}=\underbrace{Y^{1-\theta}}_{=A} \underbrace{e^{\theta z_{i t}}}_{=e^{\nu_{i t}}}\left(k_{i t}^{\alpha} l_{i t}^{1-\alpha}\right)^{\theta} \text {. }
$$

Therefore, this model is equivalent to the baseline firm-level model discussed in Section 3: $A=Y^{1-\theta} B^{\theta}, \nu_{i t}=\theta z_{i t}, \omega_{i t}=\theta \epsilon_{i t}$ and $\psi_{i t}=\theta \eta_{i t}$.

Definition 1. An equilibrium in this economy is defined by a pair $(w, Y)$ such that:

1. The labor market is in equilibrium: $L^{s}=L_{0}\left(\frac{w}{w_{0}}\right)^{\epsilon}=\int_{i} l_{i t} d i=L^{d}$.

2. Total output is the sum of firm-level output: $Y=\int_{i} p_{i t} y_{i t} d i$.

Given a general equilibrium, aggregate TFP in this economy admits a simple expression:

$$
T F P=\frac{Y}{K^{\alpha} L^{1-\alpha}}
$$

\subsection{Building Intuitions}

Consider first the simplified setting of Section 3.3. There are no adjustment costs $\left(c_{k}=0\right)$ and no measurement error in sales forecast $\left(\sigma_{\zeta}=0\right)$. With these assumptions, it is straightforward to show that aggregate TFP depends solely on the variance of forecast errors:

$$
\log (T F P)=-\frac{\alpha}{2}\left(1+\frac{\alpha \theta}{1-\theta}\right) \operatorname{Var}\left[F E_{i t}\right]
$$

Proof. See Appendix A.3.

This formula for aggregate TFP is reminiscent of Hsieh and Klenow (2009). In this setting without adjustment costs, forecast errors made when investing are formally equivalent to a wedge between the user cost of capital and the marginal productivity of capital $\alpha \theta \frac{p_{i t} y_{i t}}{k_{i t}}$. When the log-sales forecast error turns out to be positive, the firm's capital stock is too large relative to a completely frictionless benchmark where there is no information friction, i.e. one where the firm is rational and observes productivity when investing. 
The productivity loss has two sources: the information friction (time to build) and the deviation from rationality. It follows directly from Equation (12) that, in this simple framework without adjustment costs, aggregate TFP losses due to distorted forecasts depend solely on the increase in the variance of the log-sales forecast errors due to the forecasting bias:

$$
\log \left(T F P^{\text {rational }}\right)-\log \left(T F P^{\text {actual }}\right)=\frac{\alpha}{2}\left(1+\frac{\alpha \theta}{1-\theta}\right)\left(\operatorname{Var}\left[F E_{i t}^{\text {actual }}\right]-\operatorname{Var}\left[F E_{i t}^{\text {rational }}\right]\right)
$$

which is positive as the forecast error with bias has a bigger variance than the rational forecast error. This comes from the fact that rational forecasts have the lowest MSE.

In particular, this last expression provides a natural bound for TFP losses due to distorted forecasts:

$$
\begin{aligned}
\log \left(T F P^{\text {rational }}\right)-\log \left(T F P^{\text {actual }}\right) & <\log \left(T F P^{\text {perfect foresight }}\right)-\log \left(T F P^{\text {actual }}\right) \\
& \leq \frac{\alpha}{2}\left(1+\frac{\alpha \theta}{1-\theta}\right) \operatorname{Var}\left[F E_{i t}^{\text {actual }}\right]
\end{aligned}
$$

This bound is useful since it does not require the structural estimates in Table 6 . Given a variance of log-sales forecast error of .03, and our calibration for $\alpha$ and $\theta$, we see that, in this frictionless benchmark, TFP losses due to distorted forecasts can be at most $.38 \times .03 \approx 1.15 \%$. Given the relatively low variance of log-sales forecast errors in the data, this frictionless benchmark already informs us about the limited scope that distorted forecasts may exert on aggregate efficiency. The structural estimation allows us to obtain a precise estimate.

\subsection{TFP losses due to distorted forecasts}

As we explained in Section 3.3, results in Table 3 reject the null hypothesis of no adjustment costs. As a result, aggregate efficiency losses due to the forecasting bias observed in the data need to be inferred from the model that includes quadratic adjustment costs to capital. Since this model does not admit closed-form solutions, we proceed numerically. In Appendix A.4, we show a simple methodology to compute the difference in aggregate log-TFP between the actual economy and the counterfactual economy with rational expectations. In a first step, we can calculate the average capital stock $\left(K^{*}\right)$ and the average sales $Y^{*}$ in an economy where $w=Y=1$ and firms long-term productivity is 0 (for all $\mathrm{i}, \mathcal{V}_{i}=0$ ): this is easily done by simulating the 
solution to the Bellman problem in Equation 8. In a second step, we can calculate the same quantities for an economy where again, $w=Y=1$ and $\mathcal{V}_{i}=0$ for all firms, but where managers hold rational expectations: denote these quantities by $\left(K_{0}^{*}, Y_{0}^{*}\right)$. As we show in Appendix A.4, aggregate TFP losses due to distorted forecasts are then given by:

$$
\log \left(\text { TF } P_{0}\right)-\log (\text { TFP })=\alpha\left(\log \left(K^{*}\right)-\log \left(K_{0}^{*}\right)\right)+\frac{1-(1-\alpha) \theta}{\theta}\left(\log \left(Y_{0}^{*}\right)-\log \left(Y^{*}\right)\right)
$$

Quantitatively, we find that TFP losses due to biases in managerial forecasts are:

$$
\log \left(T F P^{\text {rational }}\right)-\log \left(T F P^{\text {actual }}\right)=0.10 \%
$$

These TFP losses are an order of magnitude smaller than the partial equilibrium loss in value discussed in Section 3.5. Unsurprisingly, general equilibrium forces dampen the effect of forecasting biases observed in partial equilibrium. Quantitatively, these general equilibrium effects are large and lead us to conclude that the significant distortion on forecasting estimated in Table 6 have negligible implications for aggregate efficiency.

\section{Alternative calibration for $\alpha$ and $\theta$}

In this section, we explore the robustness of our findings to alternative specification of $\alpha$, the capital share in production, and $\theta$, the price elasticity of demand. In our baseline estimation, $\alpha$ is set to .33 and $\theta$ is set to .8. We consider two sensitivity analyses. First, we set $\theta$ to .8 , but let $\alpha$ vary from .2 to .5. Second, we set $\alpha$ to .33, but let $\theta$ vary from .6 to .9. For each alternative calibration, we re-estimate our model. Note that a different calibration for $\alpha$ and $\theta$ changes the model, but also the empirical moments related to TFP: an alternative calibration leads to a different set of TFP residuals, and therefore different estimates for $\hat{\chi}, \sigma_{\tau}$ and $\sigma_{V}$. Once the model are re-estimated, we compute the partial equilibrium value loss from distorted forecasts, in a similar fashion to what we did in Section 3.5. We also compute the general equilibrium TFP losses from distorted forecasts, as we did in Section 4.3.

We present the results graphically in Figure 6. The upper panel shows the partial equilibrium value losses for alternative calibration of $\alpha$ and $\theta$. As expected, these value losses increase with $\alpha$, the share in production of the distorted inputs, and $\theta$, 
the decreasing returns to scale in revenues. However, we also see that the magnitudes of the estimated losses remain quantitatively similar to our baseline estimate. In our baseline estimate, we estimated value losses of $0.54 \%$ and TFP losses of $0.08 \%$. When $\alpha$ is calibrated at .5 (large capital share), value losses are about $1 \%$ and TFP losses about $.15 \%$. When $\theta$ is calibrated at .9 (high degree of substitution across inputs in final good production), value losses are about $2 \%$ and TFP losses about .12\%.

\section{Optimism, Pessimism and Underreaction}

Column (1) and (3) of Table 4 documents strong persistence in log-sales forecast errors. Our interpretation of this finding so far is that managers underrreact to news about future TFP. However, this persistence could originate from a constant bias in beliefs. Some managers may be over-optimistic, while others may be over-pessimistic (e.g., Malmendier and Tate (2005), Landier and Thesmar (2009) or Ben-David et al. (2013)). We entertain this possibility in Column (2) and (4) of Table 4. In these specifications, we control for firm fixed-effect. To avoid well-known biases in the estimation of persistence in the presence of individual fixed-effects and small T (Nickell (1981)), we restrict the sample to firms for which we observe at least 9 forecast errors and use dynamic panel GMM (e.g. Arellano and Bover (1995)). The estimated AR(1) coefficient for log-sales forecast error remains statistically significant, but its magnitude drop from about .3 to about .15. The estimation implies a volatility of fixed-effects in managerial forecast errors of $7.6 \%$.

To estimate the economic magnitude of these findings, we augment the model introduced in Section 3 to allow for a pessimism / optimism bias. Precisely, we assume that firm i's manager perceives her long-term productivity to be $b_{i}$, with $b_{i} \sim \mathcal{N}\left(0, \sigma_{b}^{2}\right)$ and $b_{i}$ and $\mathcal{V}_{i}$ are assumed to be independent. The manager therefore perceives the dynamics of $\nu$ to be:

$$
\nu_{i t} \stackrel{\mathbb{R}}{\sim} \mathcal{N}((1-\rho)\left(\mathcal{V}_{i}+b_{i}\right)+\rho \nu_{i t-1}+\psi_{i t}+\underbrace{\gamma \rho \omega_{i t-1}}_{\text {over/underreaction }}, \sigma_{\omega}^{2})
$$

Introducing optimism / pessimism $b_{i}$ is formally equivalent to increasing the firm's (perceived) long-term productivity by $b_{i}$. As a result, the value and optimal investment policy of a manager with a fixed bias $b_{i}$ and long-term productivity $\mathcal{V}_{i}$ derives directly from the value and investment policy of a firm with no bias $\left(b_{i}=0\right)$ and a 
long-term productivity of $0\left(\mathcal{V}_{i}=0\right)$. Let $k^{*}\left(k_{i t} ;\left(\nu_{i t}, \omega_{i t}, \psi_{i t+1}\right)\right)$ be the optimal policy function in this case and $V\left(k_{i t} ;\left(\nu_{i t}, \omega_{i t}, \psi_{i t+1}\right)\right)$ its optimal value. The optimal policy function $k^{i, *}\left(k_{i t} ;\left(\nu_{i t}, \omega_{i t}, \psi_{i t+1}\right)\right)$ of a firm with long-term productivity $\mathcal{V}_{i}$ and optimism / pessimism $b_{i}$ can be expressed as:

$$
k^{i, *}\left(k_{i t} ;\left(\nu_{i t}, \omega_{i t}, \psi_{i t+1}\right)=e^{\frac{\mathcal{\nu}_{i}+b_{i}}{1-\theta}} \times k^{*}\left(\frac{k_{i t}}{e^{\frac{\nu_{i}+b_{i}}{1-\theta}}} ;\left(\nu_{i t}-\left(\mathcal{V}_{i}+b_{i}\right), \omega_{i t}, \psi_{i t+1}\right)\right)\right.
$$

We use this equation to simulate data from a model where firms may have longterm productivity $\mathcal{V}_{i} \sim \mathcal{N}\left(0, \sigma_{\mathcal{V}}^{2}\right)$ and fixed pessimism / optimism bias $b_{i} \sim \mathcal{N}\left(0, \sigma_{b}^{2}\right)$. Appendix A.5 shows precisely how to solve the model in this case.

We take the extended model to the data. Our estimation procedure is similar to the estimation described in Section 3.2, with two modifications. First, we use $\chi_{F E}=\frac{\operatorname{Var}\left(F E_{i t}-F E_{i t-2}\right)}{\operatorname{Var}\left(F E_{i t}-F E_{i t-1}\right)}$ to identify the persistence of log-sales forecast errors in the presence of fixed belief biases. Second, we calculate $\mathbb{V}_{\mathrm{FE}}$ the variance of $\frac{F E_{i t}-\widehat{\chi_{\mathrm{FE}}} F E_{i t-1}}{1-\bar{\chi}_{F E}}$ to identify the variance of the belief fixed-effects $b_{i}$. We match these two moments, as well the other six moments described in Section 3.2. Given the estimated parameters, Appendix A.5 also shows how to compute aggregate TFP in this economy. Aggregate TFP losses from distorted forecasts are then simply calculated by comparing aggregate TFP in this economy with aggregate TFP in an economy with $\gamma=\sigma_{b}=0$.

Table 7 presents the results. The estimated structural parameters are mostly similar to the ones estimated in Table 6, with one exception: the estimated $\gamma$ is now -.29 as opposed to -.56 in Panel B of Table 6. This result is not surprising: the estimated persistence in forecast errors is smaller when we allow for firm fixed-effects (Table 4) so that the model naturally finds less under-reaction. However, the smaller estimated value for $\gamma$ implies a large and significant dispersion for the variance of $b_{i}$, the pessimism/optimism bias that managers exhibit: the estimate for $\sigma_{b}$ is .049 , which implies that about $10 \%$ of the variance in forecast errors can be attributed to fixed optimism/pessimism bias.

The last line in Table 7 reports the TFP losses due to distortions in forecast in this economy. We find that, relative to a rational expectation counterfactual $\left(\sigma_{b}=0=\gamma\right)$, TFP in the actual economy is lower by $.14 \%$. This aggregate efficiency loss is close to what we report in Table 6, Panel B $(0.10 \%)$ : on the one hand, in this economy with optimism/pessimism bias, managers exhibit under-react less to news about TFP, which reduces the potential efficiency gains of rational expectations; on the other hand, the existence of fixed biases in beliefs increase the distortions generated by non-rational expectations. Overall, the potential aggregate TFP gains in this economy 
have the same order of magnitude than in the economy where all the belief distortions emanate from under-reaction.

\section{Conclusion}

This paper leverages unique survey data on managerial forecasts to explore the real consequences of biases in managerial beliefs. We make three contributions. First, we document pervasive and significant persistence in managerial forecast errors, consistent with managerial inattention. Second, we estimate a quantitative model of firm dynamics that accounts jointly for: (1) the dynamics of beliefs, and in particular, the variance and persistence of forecast errors (2) the dynamics of productivity (3) the link between investment and beliefs. The estimated model implies large deviations from rational expectations and significant distortions in firm-level investment. However, the effect on firm value is limited. Finally, we nest this model in a standard general equilibrium framework to assess the contribution of distortions in managerial forecasts to aggregate inefficiency. Our quantitative analysis implies negligible aggregate losses, despite significant distortions in firm-level forecasts. 


\section{References}

Akerlov, George and Janet Yellen, "Can Small Deviations from Rationality Make Significant Differences to EconomicEquilibria?," American Economic Review, 1985, $75,708-720$.

Arellano, Manuel and Olympia Bover, "Another look at the instrumental variable estimation of error-components models," Journal of Econometrics, July 1995, 68 (1), $29-51$.

Barrero, Jose Maria, "The Micro and Macro Implications of Managers' Subjective Beliefs," Technical Report, Stanford 2018.

Ben-David, Itzhak, John Graham, and Campbell Harvey, "Managerial Miscalibration," Quarterly Journal of Economics, 2013, 128, 1547-1584.

Bloom, Nicholas, Steven J. Davis, Lucia Foster, Brian Lucking, Scott Ohlmacher, and Itay Saporta-Eksten, "Business-Level Expectations and Uncertainty," Technical Report, Stanford December 2017.

Bordalo, Pedro, Nicola Gennaioli, and Andrei Shleifer, "Diagnostic expectations and credit cycles," Journal of Finance, 2017.

_, _, Rafael LaPorta, and Andrei Shleifer, "Diagnostic Expectations and Stock Returns," Journal of Finance, 2019, Forthcoming.

_, _, Yueran Ma, and Andrei Shleifer, "Overreaction in Macroeconomic Expectations," Technical Report 2018.

Bouchaud, Jean-Philippe, Philipp Krueger, Augustin Landier, and David Thesmar, "Sticky Expectations and the Profitability Anomaly," Forthcoming Journal of Finance, 2018.

Coibion, Olivier and Yuriy Gorodnichenko, "Information Rigidity and the Expectations Formation Process: A Simple Framework and New Facts," American Economic Review, 2015.

Cooper, Russell W. and John C. Haltiwanger, "On the Nature of Capital Adjustment Costs," The Review of Economic Studies, 2006, 73 (3), 611-633.

David, Joel and Venky Venkateswaran, "The Sources of Capital Misallocation," American Economic Review, 2019. 
_, Hugo Hopenhayn, and Venky Venkateswaran, "Information, Misallocation, and Aggregate Productivity," Quarterly Journal of Economics, 2016, 131, 943-1005.

Dixit, Avinash K and Joseph E Stiglitz, "Monopolistic Competition and Optimum Product Diversity," American Economic Review, June 1977, 67 (3), 297-308.

Edwards, W, "Conservatism in Human Information Processing," in B. Kleinmuntz (ed.), ed., Formal Representation of Human Judgment, Wiley, New York, 1968, pp. $17-52$.

Gennaioli, Nicola, Yueran Ma, and Andrei Shleifer, "Expectations and investment," NBER Macroeconomics Annual, 2016, 30 (1), 379-431.

Giglio, Stefano, Matteo Maggiori, Johannes Stroebel, and Steven Utkus, "Five Facts About Beliefs and Portfolios," Technical Report 2019.

Hassan, Tarek and Thomas Mertens, "The Social Cost of Near-Rational Investment," American Economic Review, 2017, 107, 1059-1103.

Hayashi, Fumio, “Tobin's Marginal q and Average q: A Neoclassical Interpretation," Econometrica, January 1982, 50 (1), 213-224.

Hirshleifer, David, Angie Low, and Siew-Hong Teoh, "Are Overconfident CEOs Better Innovators?, The Journal of Finance, 2012, 67 (4), 1457-1498.

Hsieh, Chang-Tai and Peter Klenow, "Misallocation and Manufacturing TFP in China and India," Quarterly Journal of Economics, 2009.

Landier, Augustin and David Thesmar, "Financial Contracting with Optimistic Entrepreneurs: Theory and Evidence," Review of Financial Studies, 2009, 22, 117150 .

Lo, Andrew W. and A. Craig MacKinlay, "Stock Market Prices do not Follow Random Walks: Evidence from a Simple Specification Test," The Review of Financial Studies, 1988, 1 (1), 41-66.

Malmendier, Ulrike and Geoffrey Tate, "CEO Overconfidence and Corporate Investment," Journal of Finance, 2005, 60, 2661-2700.

- and Stefan Nagel, "Learning from Inflation Experiences," Quarterly Journal of Economics, 2016, 131, 53-87. 
Nickell, Stephen, "Biases in Dynamic Models with Fixed Effects," Econometrica, 1981, 49 (6), 1417-26. 


\section{FIGURES}

Figure 1: Forecast Errors: Histogram

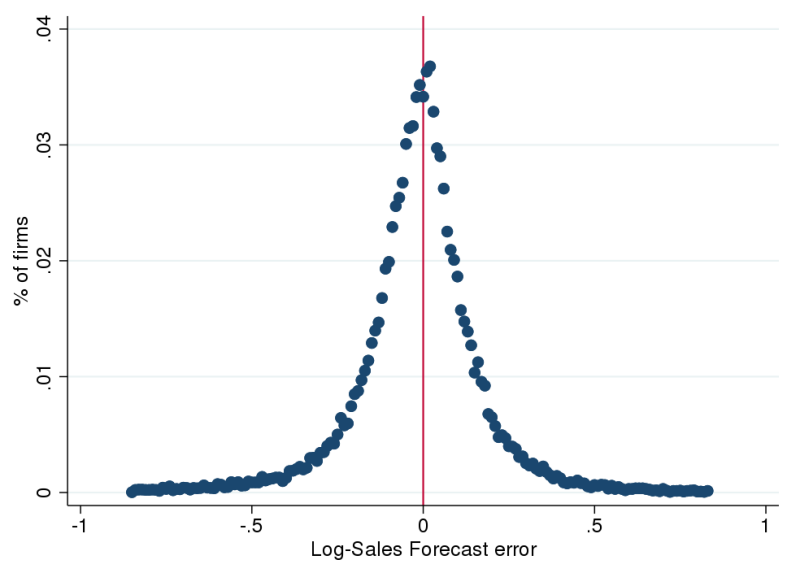

Note: This figure plots the distribution of log-sales forecast errors. The log-sales forecast error is computed as the difference between realized sales in fiscal year $t$ and sales forecast for year $t$ issued at the beginning of year $t$.

Figure 2: Forecast Error Persistence: Binned Scatter Plot

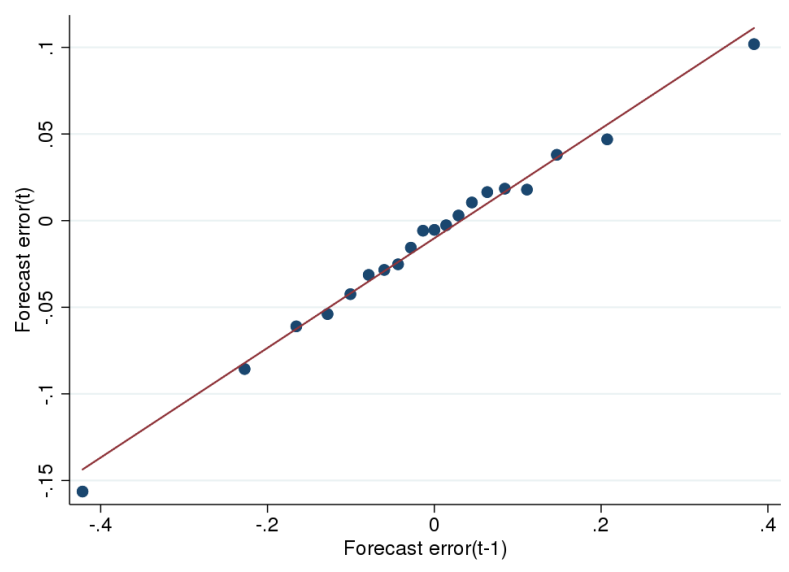

Note: This figure is a binscatter plot of year $t$ log-sales forecast error on year $t-1$ log-sales forecast error. 
Figure 3: Numerical Comparative statics
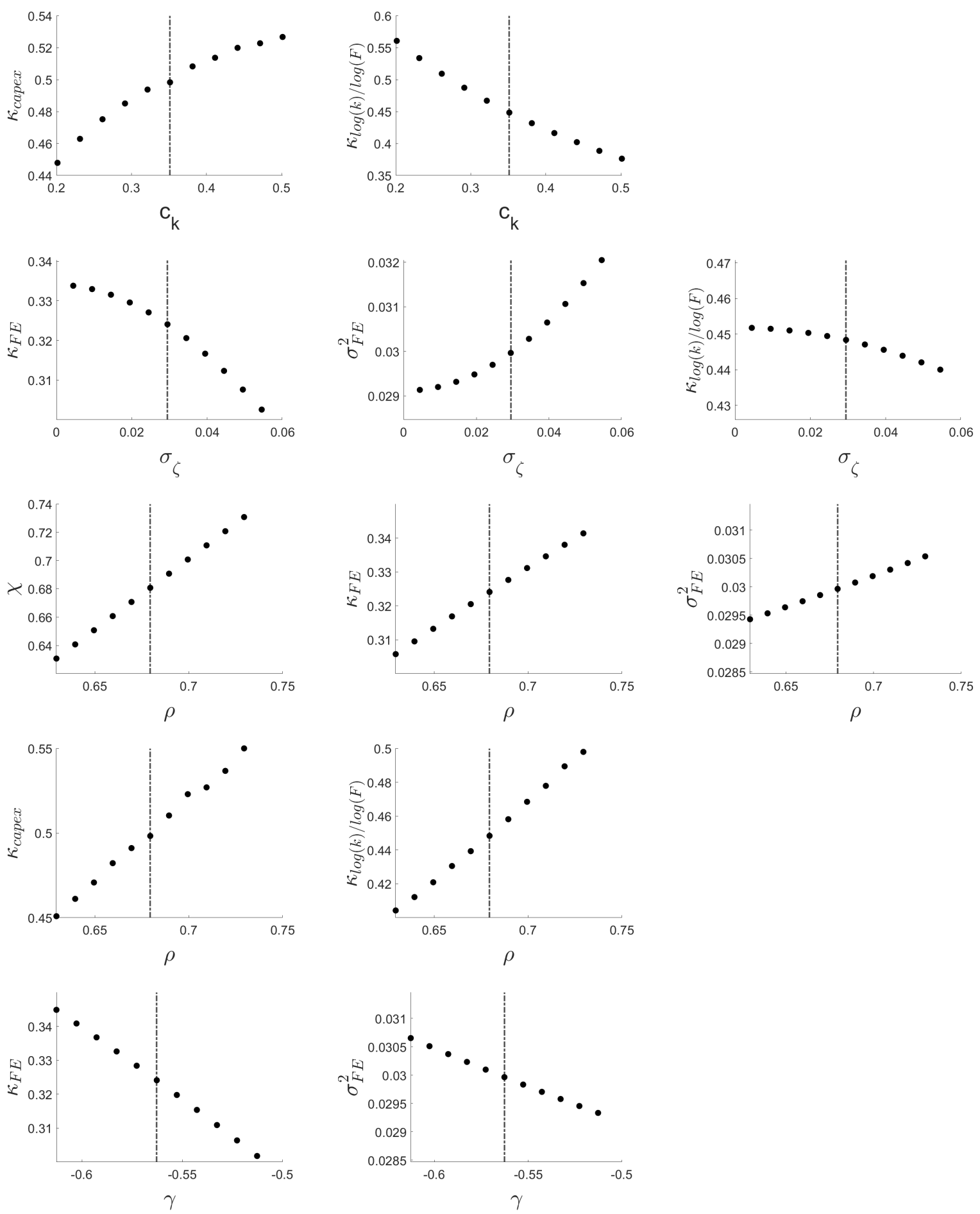
Figure 3: Numerical Comparative statics (continued)
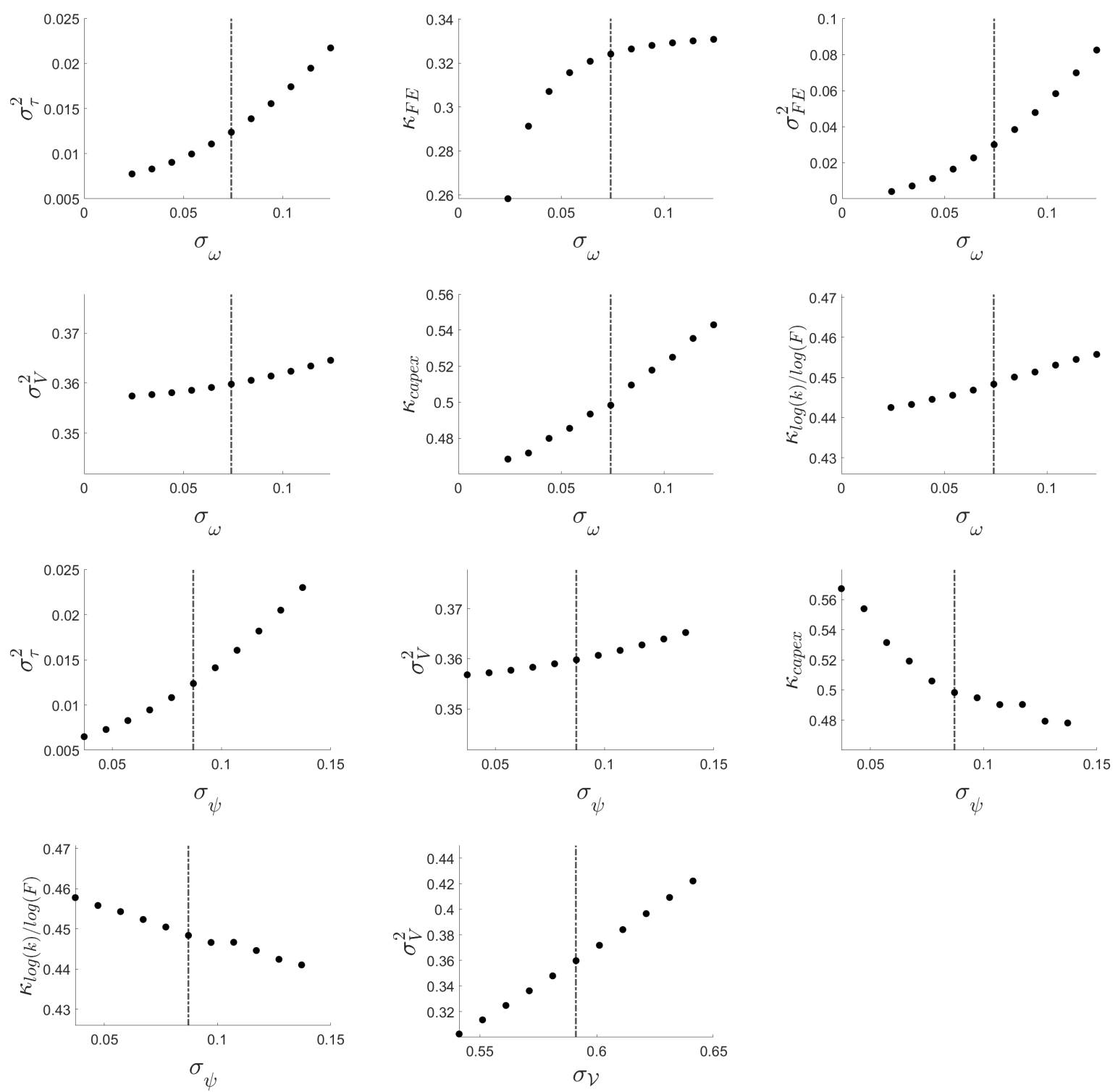

Note: This table provides numerical comparative statics for our simulated model. For each of the seven estimated parameters $\left(c_{k}, \sigma_{\zeta}, \rho, \gamma, \sigma_{\omega}, \sigma_{\psi}, \sigma_{\mathcal{V}}^{2}\right)$, we compute the seven simulated moments $\left(\chi, \sigma_{\tau}^{2}, \kappa_{\mathrm{FE}}, \sigma_{\mathrm{FE}}^{2}, \sigma_{\mathcal{V}}^{2}, \kappa_{\text {capex }}, \kappa_{\log (k) / \log (\mathbb{F})}\right)$ for values of the parameters in the neighborhood of their estimated values (vertical dashed line). We report only the parameter-moment pair for which variations in the parameter lead to non-zero variations in simulated moments. 
Figure 4: Firm Investment with Rational vs. Distorted Forecasts

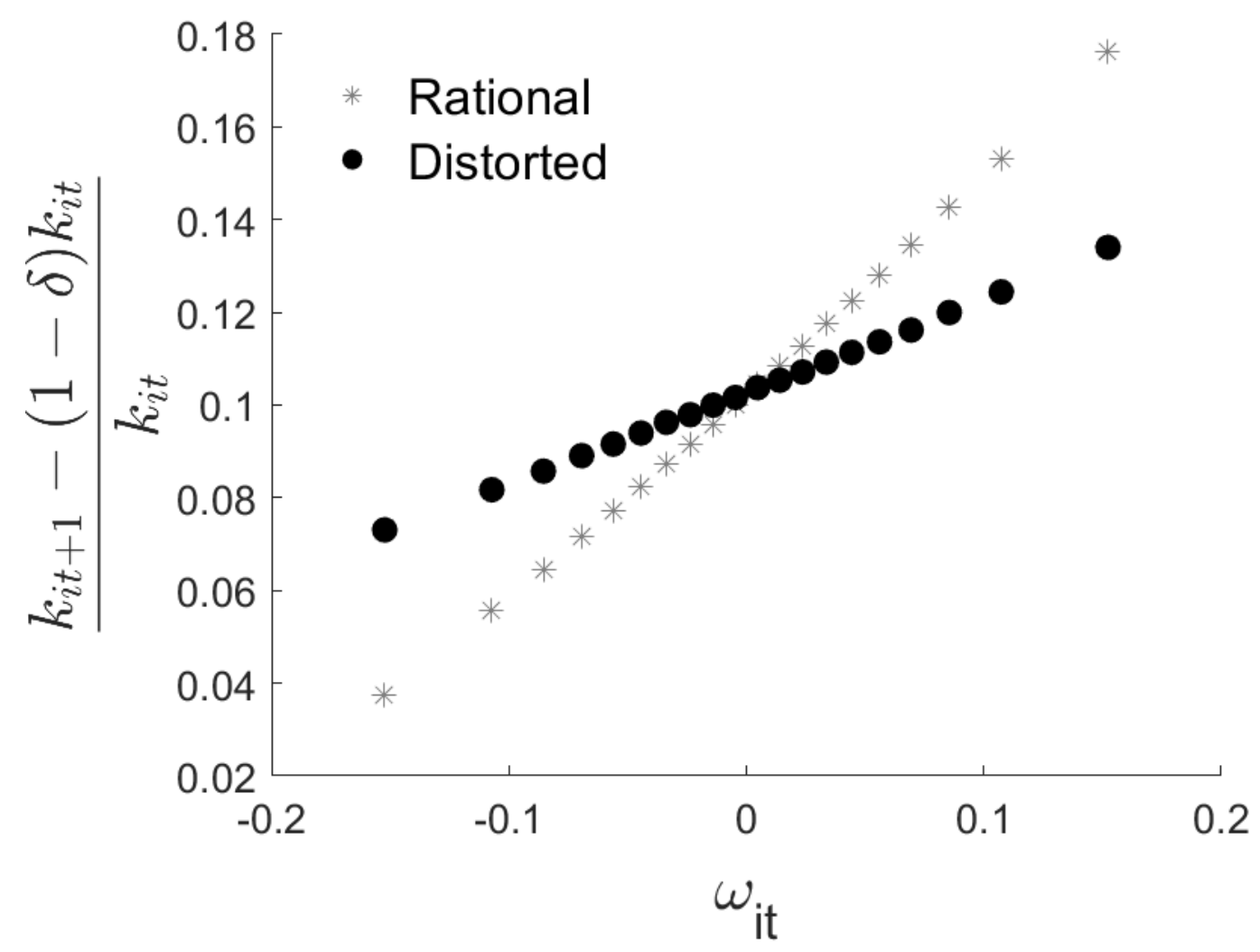

Note: This figure uses the estimation of Table 6 to simulate investment for managers using rational forecast (grey stars) or distorted forecasts (dark circles). We construct 20 vingitiles of date $t$ TFP innovations $\left(\omega_{i t}\right)$ and compute, for each of these bins, the average investment ratio for both managers with rational forecasts $(\gamma=0)$ and managers with distorted forecasts ( $\gamma$ set at its estimated value). 
Figure 5: Firm Value with Rational vs. Distorted forecasts

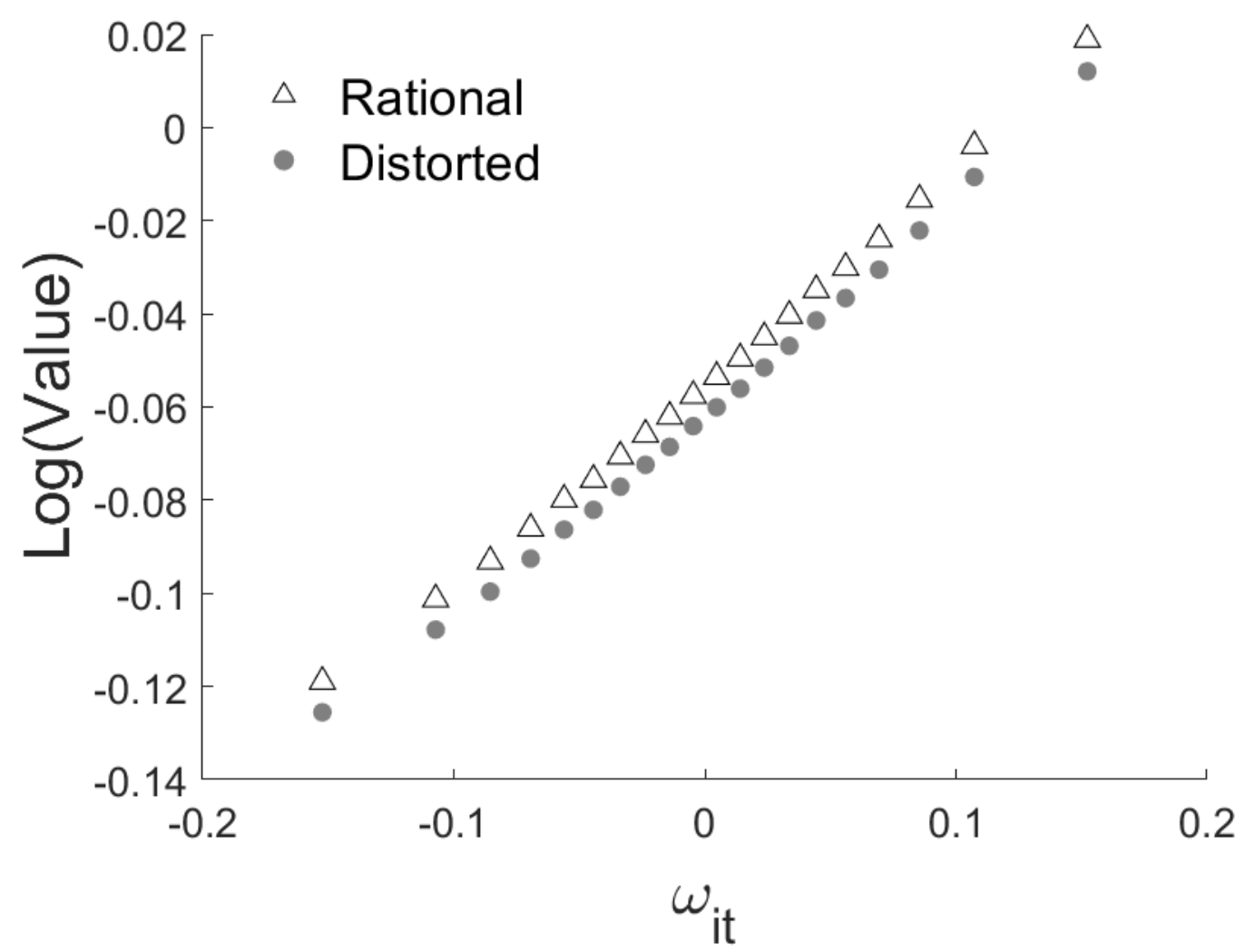

Note: This figure uses the estimation of Table 6 to simulate firm value for managers using distorted forecasts ( $\gamma$ at its estimated value) relative to managers using rational forecasts $(\gamma=0)$. We construct 20 vingitiles of date t TFP innovations $\left(\omega_{i t}\right)$ and compute, for each of these bins, the average firm value of rational managers (white triangles) and managers with distorted forecasts (grey circles). 
Figure 6: TFP losses and Value Losses with alternative calibration
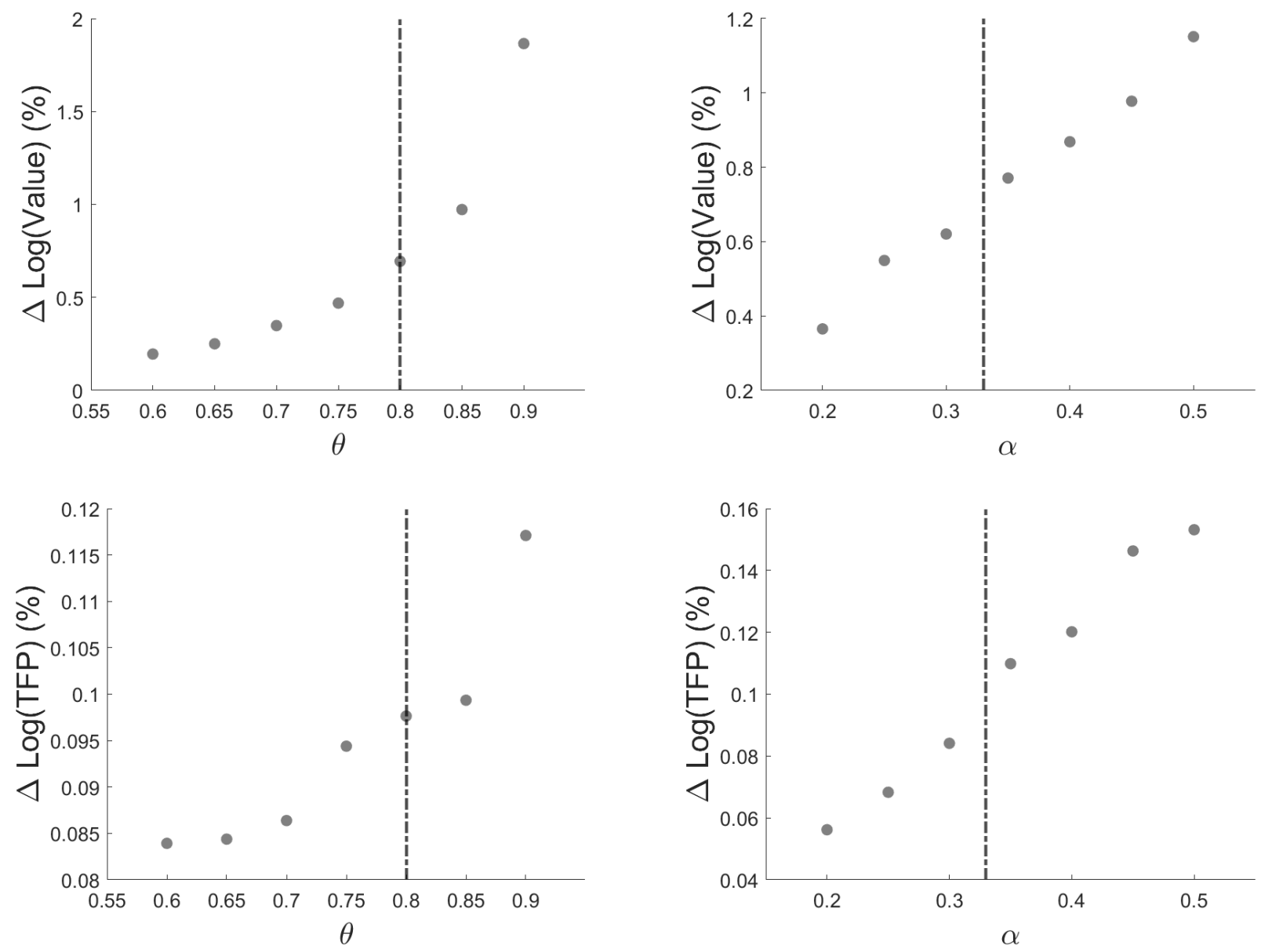

Note: the top panel computes value losses from distorted managerial forecasts for alternative calibration of $\alpha$ and $\theta$. The methodology to compute these losses is described in Section 3.5. The bottom panel computes aggregate TFP losses from distorted managerial forecasts for alternative calibration of $\alpha$ and $\theta$. The methodology to compute these losses is described in Section 4.3. 


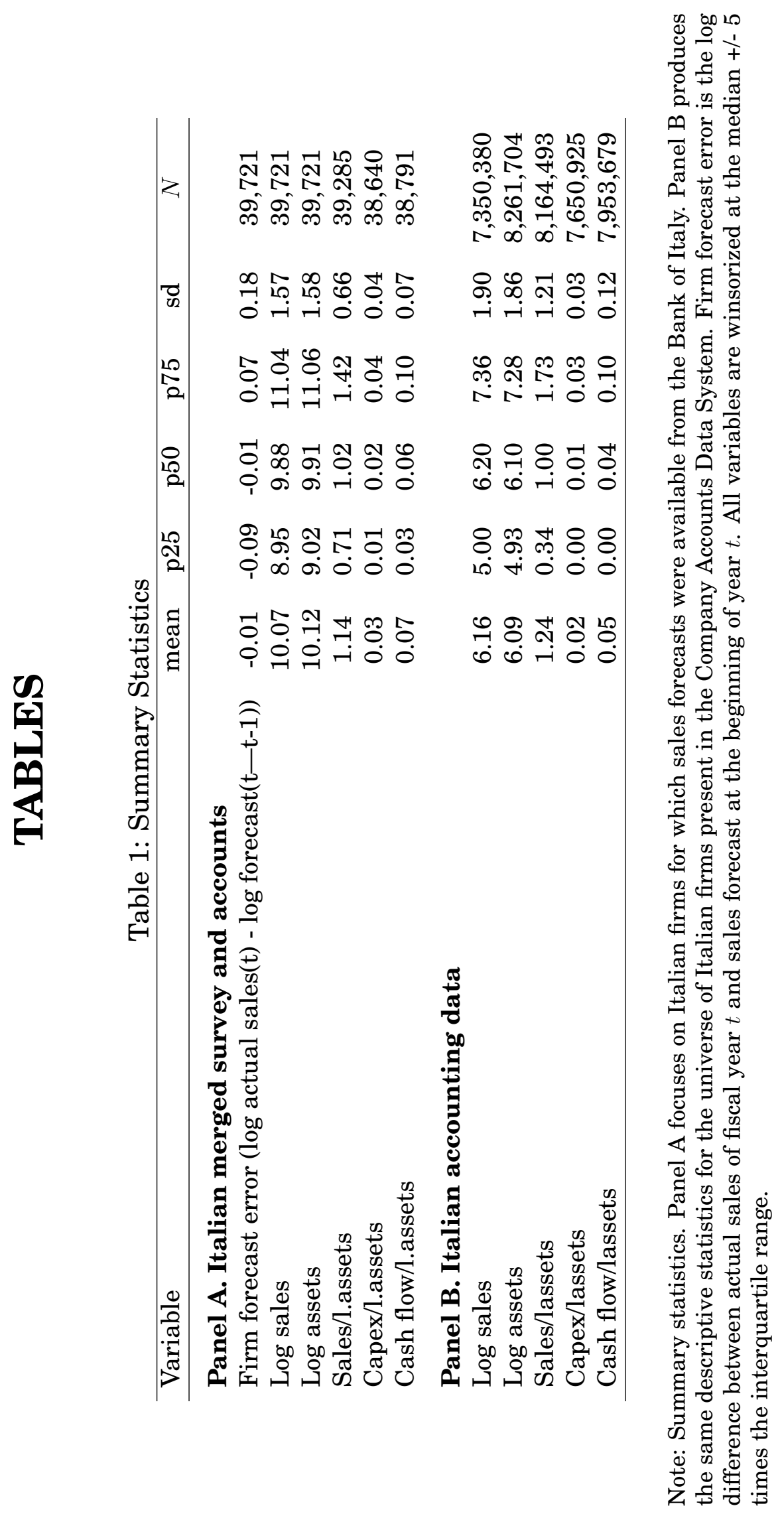




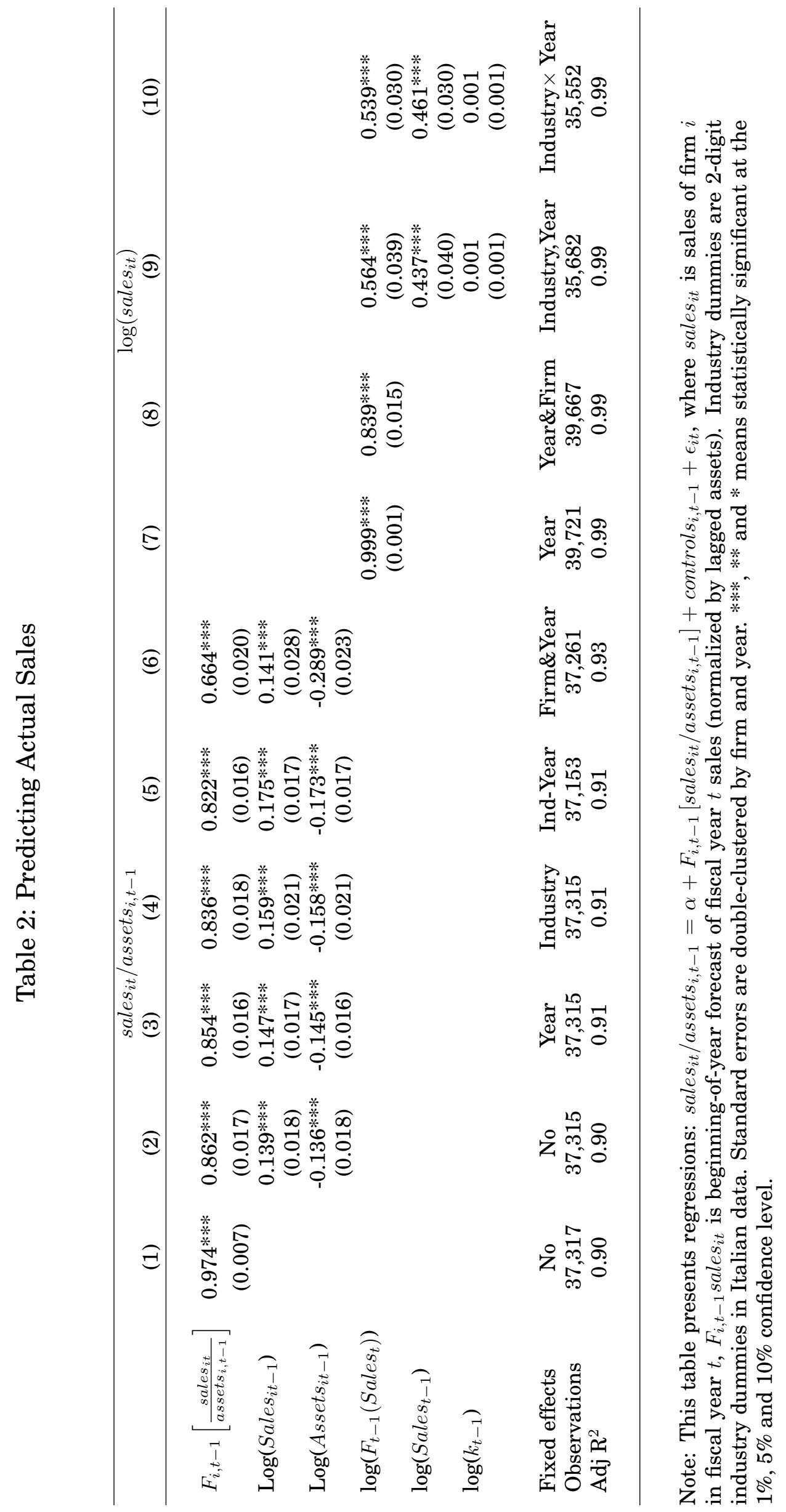




\section{Table 3: Sales Forecasts and Capital Investment}

\begin{tabular}{|c|c|c|}
\hline & \multicolumn{2}{|c|}{$\log k_{i t}$} \\
\hline & $\begin{array}{l}\text { Manufacturing } \\
\text { Only } \\
\text { (1) }\end{array}$ & $\begin{array}{l}\text { All } \\
\text { Firms } \\
(2)\end{array}$ \\
\hline $\log \left(F_{t-1}\left(\right.\right.$ Sales $\left.\left._{i t}\right)\right)$ & $\begin{array}{c}0.366^{* * * *} \\
(0.034)\end{array}$ & $\begin{array}{c}0.410^{* * *} \\
(0.034)\end{array}$ \\
\hline Fixed effects & Firm \& Year & Firm \& Year \\
\hline Observations & 24,891 & 36,996 \\
\hline $\operatorname{Adj} R^{2}$ & 0.92 & 0.93 \\
\hline
\end{tabular}

Note: This table presents estimates of the following linear model: $\log k_{i t}=\alpha_{i}+\delta_{t}+$ $\kappa_{\log (k) / \log (\mathbb{F})} \log F_{i t-1}$ sales $_{i t}+\epsilon_{i t}$. The dependent variable $\log k_{i t}$ is the log of capital (net tangible fixed assts) at the end of year $t$ while $\log F_{i, t-1}$ sales $_{i t}$ is the log of beginning-of-year forecast of fiscal year $t$ sales. Column (1) estimates $\kappa_{\log (k) / \log (\mathbb{F})}$ on the sample of manufacturing firms. Column (2) estimates $\kappa_{\log (k) / \log (\mathbb{F})}$ for all firms in the sample. Standard errors are double-clustered by firm and year. ***, ** and * means statistically significant at the $1 \%, 5 \%$ and $10 \%$ confidence level. 


\section{Table 4: Persistence of Forecast Errors}

\begin{tabular}{|c|c|c|c|c|}
\hline & \multicolumn{4}{|c|}{ Log-sales forecast error $\left(\widehat{F E}_{i t}\right)$} \\
\hline & \multicolumn{2}{|c|}{ Manufacturing } & \multicolumn{2}{|c|}{ All firms } \\
\hline & $(1)$ & $(2)$ & (3) & $(4)$ \\
\hline$\widehat{F E}_{i t-1}$ & $\begin{array}{c}0.289 * * * \\
(0.021)\end{array}$ & $\begin{array}{c}0.159 * * * \\
(0.015)\end{array}$ & $\begin{array}{c}0.321^{* * * *} \\
(0.017)\end{array}$ & $\begin{array}{c}0.176^{* * * *} \\
(0.014)\end{array}$ \\
\hline Year FE & Yes & Yes & Yes & Yes \\
\hline Firm FE & No & Yes & No & Yes \\
\hline Observations & 23,458 & 14,255 & 34,001 & 19,744 \\
\hline $\operatorname{Adj} R^{2}$ & 0.11 & & 0.12 & \\
\hline
\end{tabular}

Note: This table presents estimation results for the following linear regression model: $\widehat{F E}_{i t}=\delta_{t}+$ $\kappa_{F E} \widehat{F E}_{i t-1}+\epsilon_{i t}$, where $\widehat{F E}_{i t}$ is the log-sales forecast error (log actual sales minus log sales forecast made in first quarter of fiscal year $t$ ). Columns (1) and (3) only includes year fixed-effects. Columns (2) and (4) add firm fixed-effects, and are estimated using dynamic panel GMM (Arellano and Bover (1995)) on the sample of firms with at least 9 sales forecasts. Standard errors are double clustered by firm and year. ${ }^{* * *}, * *$ and $*$ means statistically significant at the $1 \%, 5 \%$ and $10 \%$ confidence level. 
Table 5: Persistence of Forecast Errors: by Firm Size

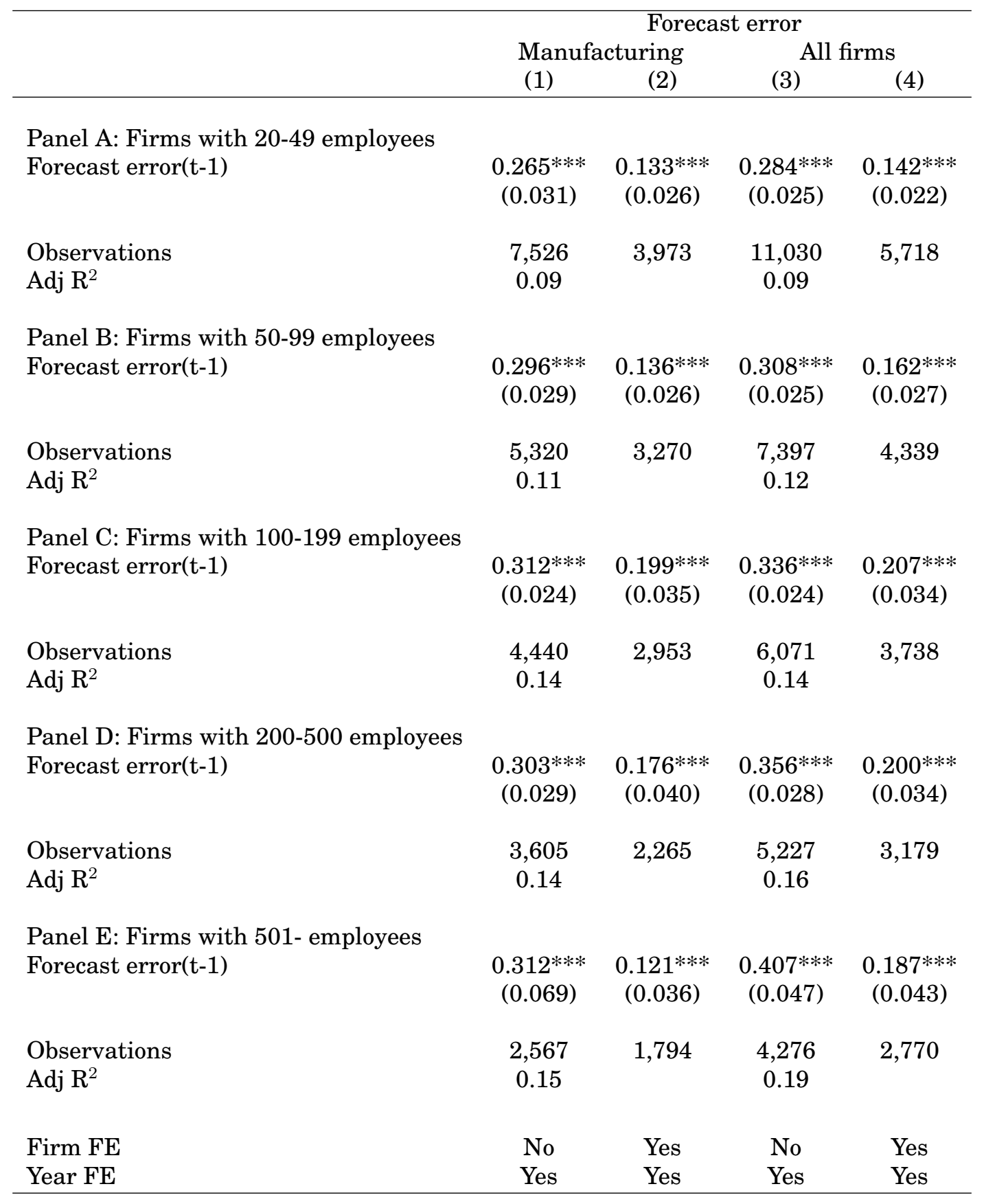

Note: This table presents estimation results for the following linear regression model: $\widehat{F E}_{i t}=\delta_{t}+$ $\gamma \widehat{F E}_{i t-1}+\epsilon_{i t}$. Columns (1), (3) only includes year fixed-effects. Columns (2), (4) add firm fixed-effects, and are estimated using dynamic panel GMM (Arellano and Bover (1995)) on the sample of firms with at least 9 sales forecasts. Standard errors are double clustered by firm and year. Panel A (resp. B, C, $\mathrm{D}$, and E) estimates the model using only firms with 20-49 employees (resp. 50-99, 100-199, 200-500, and more than 500 ). $* * *, * *$ and $*$ means statistically significant at the $1 \%, 5 \%$ and $10 \%$ confidence levels. 
Table 6: Structural Estimation: baseline estimate

Panel A: Manufacturing firms

Estimates:

$\begin{array}{ccccccc}c_{k} & \sigma_{\zeta} & \rho & \gamma & \sigma_{\omega} & \sigma_{\psi} & \sigma_{\mathcal{V}} \\ & & & & & & \\ 0.387 & 0.031 & 0.649 & -0.509 & 0.077 & 0.091 & 0.515 \\ (0.037) & (0.110) & (0.025) & (0.149) & (0.012) & (0.010) & (0.020)\end{array}$

Moments:

$\begin{array}{lccccccc} & \chi & \sigma_{\tau}^{2} & \kappa_{\mathrm{FE}} & \sigma_{\mathrm{FE}}^{2} & \sigma_{V}^{2} & \kappa_{\text {capex }} & \kappa_{\log (k) / \log (\mathbb{F})} \\ \text { Data } & & & & & & & \\ \text { Model } & 0.762 & 0.013 & 0.289 & 0.031 & 0.275 & 0.461 & 0.366 \\ \text { Difference } & 0.650 & 0.013 & 0.289 & 0.031 & 0.284 & 0.476 & 0.400 \\ & 0.112 & -0.000 & -0.000 & 0.000 & -0.009 & -0.015 & -0.034\end{array}$

Implied TFP loss:

$0.08 \%$

Panel B: All firms

Estimates:

$\begin{array}{ccccccc}c_{k} & \sigma_{\zeta} & \rho & \gamma & \sigma_{\omega} & \sigma_{\psi} & \sigma_{\mathcal{V}} \\ & & & & & & \\ 0.351 & 0.029 & 0.679 & -0.563 & 0.074 & 0.087 & 0.591 \\ (0.025) & (0.062) & (0.021) & (0.096) & (0.007) & (0.006) & (0.027)\end{array}$

Moments:

$\begin{array}{lccccccc} & \chi & \sigma_{\tau}^{2} & \kappa_{\mathrm{FE}} & \sigma_{\mathrm{FE}}^{2} & \sigma_{V}^{2} & \kappa_{\text {capex }} & \kappa_{\log (k) / \log (\mathbb{F})} \\ \text { Data } & 0.812 & 0.012 & 0.321 & 0.030 & 0.358 & 0.483 & 0.410 \\ \text { Model } & 0.681 & 0.012 & 0.324 & 0.030 & 0.372 & 0.498 & 0.448 \\ \text { Difference } & 0.131 & -0.000 & -0.003 & 0.000 & -0.014 & -0.016 & -0.038\end{array}$

Implied TFP loss:

$0.10 \%$

Note: Panel A focuses on firms in the manufacturing sector; Panel B uses all firms in the sample. $\chi$ is defined as $\frac{\operatorname{Var}\left(\hat{\nu}_{i t}-\hat{\nu}_{i t-2}\right)}{\operatorname{Var}\left(\hat{\nu}_{i t}-\hat{\nu}_{i t-1}\right)}-1$, where $\hat{\nu}_{i t}$ is the TFP residual for firm $i$ in year $t . \sigma_{V}^{2}$ is defined as $\operatorname{Var}_{i}\left(\mathbb{V}_{i}\right)$, where $\mathbb{V}_{i}=\frac{1}{T} \sum_{t=1}^{T} \frac{\hat{\nu}_{i t}-\widehat{\chi} \hat{\nu}_{i t-1}}{1-\widehat{\chi}} \cdot \sigma_{\tau}^{2}$ is defined as $\operatorname{Var}\left(\hat{\nu}_{i t}-\widehat{\chi} \hat{\nu}_{i t-1}-(1-\hat{\chi}) \mathbb{V}_{i}\right) . \kappa_{F E}$ is the persistence in log-sales forecast error estimated in Column (1) and (3) of Table 4. $\sigma_{F} E^{2}$ corresponds to the variance of log-sales forecast errors net of year fixed-effects. $\kappa_{\text {capex }}$ corresponds to the autocorrelation coefficient of investment ratios and is estimated using Equation (10). $\kappa_{\log (k) / \log (\mathbb{F})}$ corresponds to the elasticity of capital to sales forecast with firm fixed-effects andzis estimated in Table 3. Standard error are computed with the delta method, where we use the inverse of the covariance matrix of empirical moments, clustered at the firm-level, as a weighting matrix. 


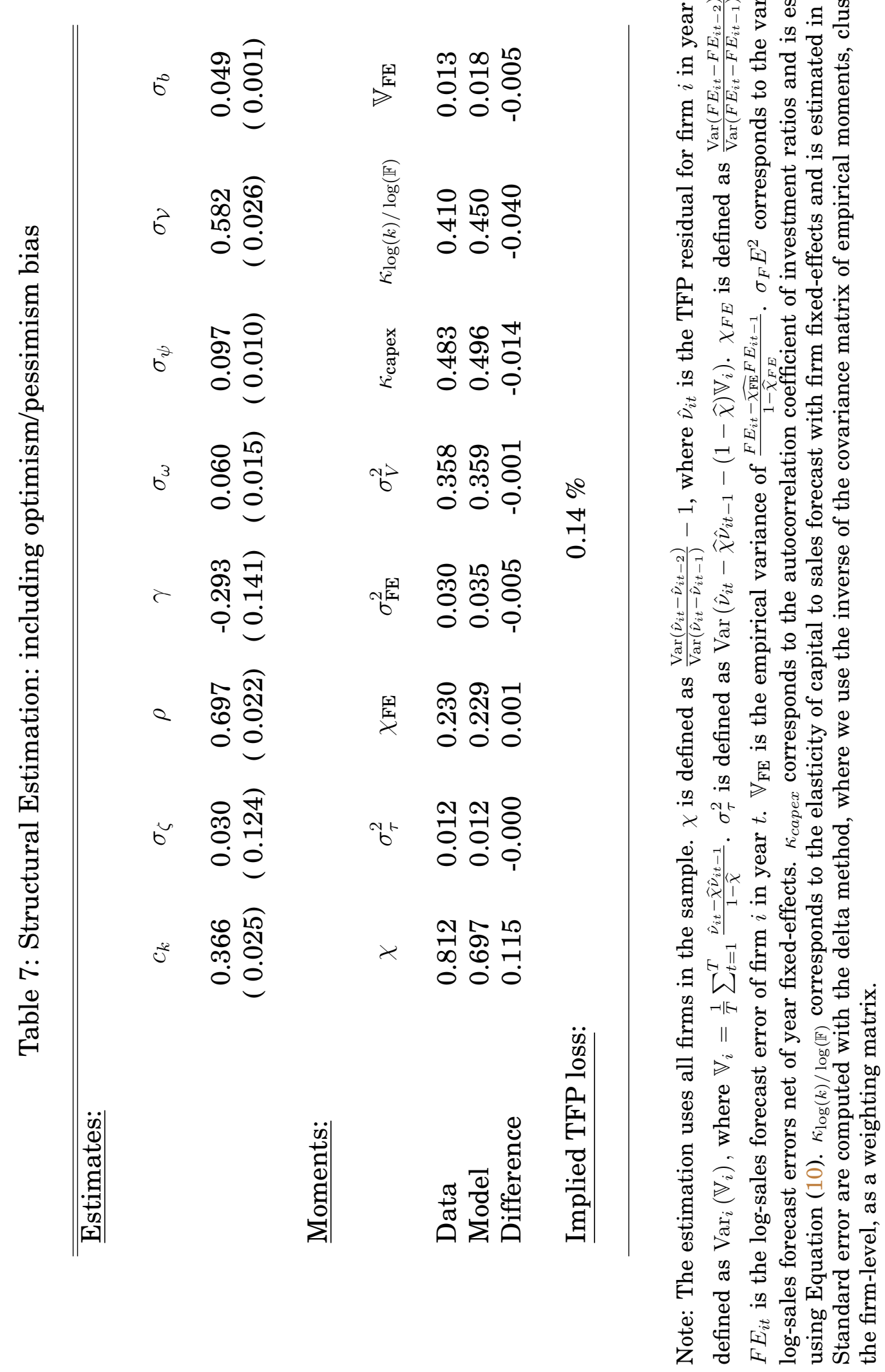




\section{APPENDIX - FOR ONLINE PUBLICATION}

\section{A Proofs}

\section{A.1 Proof for optimal investment decision}

To simplify notations, we drop the (i,t) subscripts and simply use prime superscript for next period variables. The Bellman problem of a firm with a long term productivity of 0 admits the following representation:

$$
\begin{gathered}
V\left(k ; \nu, \omega, \psi^{\prime}\right)=\max _{k^{\prime}}\left\{\Omega e^{\frac{\Phi}{\alpha \theta} \nu} k^{\phi}-\left(k^{\prime}-(1-\delta) k\right)-c_{k} \frac{\left(k^{\prime}-(1-\delta) k\right)^{2}}{k}\right. \\
\left.+\frac{1}{1+r} \mathbb{F}\left[V\left(k^{\prime} ; \nu^{\prime}, \omega^{\prime}, \psi^{\prime \prime}\right) \mid\left(\nu, \omega, \psi^{\prime}\right)\right]\right\}
\end{gathered}
$$

with:

$$
\left(\begin{array}{c}
\nu^{\prime} \\
\omega^{\prime}
\end{array}\right) \stackrel{\mathbb{F}}{\sim} \mathcal{N}\left(\left(\begin{array}{c}
\rho \nu+\gamma \rho \omega+\psi^{\prime} \\
0
\end{array}\right),\left(\begin{array}{cc}
\sigma_{\omega}^{2} & \sigma_{\omega}^{2} \\
\sigma_{\omega}^{2} & \sigma_{\omega}^{2}
\end{array}\right)\right) \text { and: } \psi^{\prime \prime} \stackrel{\mathbb{F}}{\sim} \mathcal{N}\left(0, \sigma_{\psi}^{2}\right)
$$

Let $k^{*}\left(k ; \nu, \omega, \psi^{\prime}\right)$ be the optimal policy and $V_{*}\left(k ; \nu, \omega, \psi^{\prime}\right)$ the resulting value.

Consider now the Bellman problem for a firm with a persistent component $\mathcal{V}_{i}$ in productivity:

$$
z^{\prime}=(1-\rho) \mathcal{V}_{i}+\rho z+\omega^{\prime}+\psi^{\prime}
$$

Let $V^{i}$ be the bellman value for this firm. This value admits the following representation:

$$
\begin{aligned}
V^{i}\left(k ; z, \omega, \psi^{\prime}\right)=\max _{k^{\prime}}\{ & \Omega e^{\frac{\Phi}{\alpha \theta} z} k^{\phi}-\left(k^{\prime}-(1-\delta) k\right)-c_{k} \frac{\left(k^{\prime}-(1-\delta) k\right)^{2}}{k} \\
+ & \left.\frac{1}{1+r} \mathbb{F}\left[V^{i}\left(k^{\prime} ; z^{\prime}, \omega^{\prime}, \psi^{\prime \prime}\right) \mid\left(z, \omega, \psi^{\prime}\right)\right]\right\}
\end{aligned}
$$

with:

$$
\left(\begin{array}{c}
z^{\prime} \\
\omega^{\prime}
\end{array}\right) \stackrel{\mathbb{F}}{\sim} \mathcal{N}\left(\left(\begin{array}{c}
(1-\rho) \mathcal{V}_{i}+\rho z+\gamma \rho \omega+\psi^{\prime} \\
0
\end{array}\right),\left(\begin{array}{cc}
\sigma_{\omega}^{2} & \sigma_{\omega}^{2} \\
\sigma_{\omega}^{2} & \sigma_{\omega}^{2}
\end{array}\right)\right) \text { and: } \psi^{\prime \prime} \stackrel{\mathbb{F}}{\sim} \mathcal{N}\left(0, \sigma_{\psi}^{2}\right)
$$

Define $\nu=z-\mathcal{V}_{i}$. We can rewrite the Bellman problem for firm $i$ as a function of $\nu$ instead of $z$ :

$$
\begin{aligned}
V^{i}\left(k ; \nu+\mathcal{V}_{i}, \omega, \psi^{\prime}\right)=\max _{k^{\prime}}\{ & \Omega e^{\frac{\Phi}{\alpha \theta}\left(\nu+\mathcal{V}_{i}\right)} k^{\phi}-\left(k^{\prime}-(1-\delta) k\right)-c_{k} \frac{\left(k^{\prime}-(1-\delta) k\right)^{2}}{k} \\
& \left.+\frac{1}{1+r} \mathbb{F}\left[V^{i}\left(k^{\prime} ; \nu^{\prime}+\mathcal{V}_{i}, \omega^{\prime}, \psi^{\prime \prime}\right) \mid\left(\nu, \omega, \psi^{\prime}\right)\right]\right\}
\end{aligned}
$$

with:

$$
\left(\begin{array}{c}
\nu^{\prime} \\
\omega^{\prime}
\end{array}\right) \stackrel{\mathbb{F}}{\sim} \mathcal{N}\left(\left(\begin{array}{c}
\rho \nu+\gamma \rho \omega+\psi^{\prime} \\
0
\end{array}\right),\left(\begin{array}{cc}
\sigma_{\omega}^{2} & \sigma_{\omega}^{2} \\
\sigma_{\omega}^{2} & \sigma_{\omega}^{2}
\end{array}\right)\right) \text { and: } \psi^{\prime \prime} \stackrel{\mathbb{F}}{\sim} \mathcal{N}\left(0, \sigma_{\psi}^{2}\right)
$$


We can rewrite this previous problem in a simpler fashion:

$$
\begin{aligned}
V^{i}\left(k ; \nu+\mathcal{V}_{i}, \omega, \psi^{\prime}\right)=\max _{k^{\prime}}\left\{e ^ { \frac { \mathcal { V } _ { i } } { 1 - \theta } } \left(\Omega e^{\frac{\Phi}{\alpha \theta} \nu}\left(\frac{k}{e^{\frac{\mathcal{V}_{i}}{1-\theta}}}\right)^{\phi}-\left(\left(\frac{k^{\prime}}{e^{\frac{\mathcal{V}_{i}}{1-\theta}}}\right)-(1-\delta)\left(\frac{k}{e^{\frac{\mathcal{V}_{i}}{1-\theta}}}\right)\right)\right.\right. \\
\left.\left.-c_{k} \frac{\left.\left.\left(\left(\frac{k^{\prime}}{e^{\frac{\mathcal{L}_{i}}{1-\theta}}}\right)-(1-\delta)\left(\frac{k}{e^{\frac{\mathcal{V}_{i}}{1-\theta}}}\right)\right)^{2}\right)+\frac{1}{1+r} \mathbb{F}\left[V^{i}\left(k^{\prime} ; \nu^{\prime}+\mathcal{V}_{i}, \omega^{\prime}, \psi^{\prime \prime}\right) \mid\left(\nu, \omega, \psi^{\prime}\right)\right]\right\}}{e^{\frac{\mathcal{V}_{i}}{1-\theta}}}\right)\right\}
\end{aligned}
$$

with:

$$
\left(\begin{array}{c}
\nu^{\prime} \\
\omega^{\prime}
\end{array}\right) \stackrel{\mathbb{P}}{\sim} \mathcal{N}\left(\left(\begin{array}{c}
\rho \nu+\gamma \rho \omega+\psi^{\prime} \\
0
\end{array}\right),\left(\begin{array}{cc}
\sigma_{\omega}^{2} & \sigma_{\omega}^{2} \\
\sigma_{\omega}^{2} & \sigma_{\omega}^{2}
\end{array}\right)\right) \text { and: } \psi^{\prime \prime} \stackrel{\mathbb{F}}{\sim} \mathcal{N}\left(0, \sigma_{\psi}^{2}\right)
$$

This last representation is equivalent to:

$$
\begin{aligned}
\left(\frac{V^{i}\left(k ; \nu+\mathcal{V}_{i}, \omega, \psi^{\prime}\right)}{e^{\frac{\mathcal{V}_{i}}{1-\theta}}}\right)= & \max _{k^{\prime}}\left\{\left(\Omega e^{\frac{\Phi}{\alpha \theta} \nu}\left(\frac{k}{e^{\frac{\mathcal{V}_{i}}{1-\theta}}}\right)^{\phi}-\left(\left(\frac{k^{\prime}}{e^{\frac{\mathcal{V}_{i}}{1-\theta}}}\right)-(1-\delta)\left(\frac{k}{e^{\frac{\mathcal{V}_{i}}{1-\theta}}}\right)\right)\right.\right. \\
& \left.-c_{k} \frac{\left.\left.\left(\left(\frac{k^{\prime}}{e^{\frac{\mathcal{V}_{i}}{1-\theta}}}\right)-(1-\delta)\left(\frac{k}{e^{\frac{\mathcal{V}_{i}}{1-\theta}}}\right)\right)^{2}\right)+\frac{1}{1+r} \mathbb{F}\left[\left(\frac{V^{i}\left(k^{\prime} ; \nu^{\prime}+\mathcal{V}_{i}, \omega^{\prime}, \psi^{\prime \prime}\right)}{e^{\frac{\mathcal{V}_{i}}{1-\theta}}}\right) \mid\left(\nu, \omega, \psi^{\prime}\right)\right]\right\}}{e^{\frac{\mathcal{V}_{i}}{1-\theta}}}\right)
\end{aligned}
$$

with:

$$
\left(\begin{array}{c}
\nu^{\prime} \\
\omega^{\prime}
\end{array}\right) \stackrel{\mathbb{P}}{\sim} \mathcal{N}\left(\left(\begin{array}{c}
\rho \nu+\gamma \rho \omega+\psi^{\prime} \\
0
\end{array}\right),\left(\begin{array}{cc}
\sigma_{\omega}^{2} & \sigma_{\omega}^{2} \\
\sigma_{\omega}^{2} & \sigma_{\omega}^{2}
\end{array}\right)\right) \text { and: } \psi^{\prime \prime} \stackrel{\mathbb{H}}{\sim} \mathcal{N}\left(0, \sigma_{\psi}^{2}\right)
$$

It is clear from the previous equation that:

$$
V_{*}^{i}\left(k ; \nu+\mathcal{V}_{i}, \omega, \psi^{\prime}\right)=e^{\frac{\mathcal{V}_{i}}{1-\theta}} \times V_{*}\left(\frac{k}{e^{\frac{\mathcal{V}_{i}}{1-\theta}}} ; \nu, \omega, \psi^{\prime}\right) \text { and: } k_{*}^{i}\left(k ; \nu+\mathcal{V}_{i}, \omega, \psi^{\prime}\right)=e^{\frac{\mathcal{V}_{i}}{1-\theta}} \times k_{*}\left(\frac{k}{e^{\frac{\mathcal{V}_{i}}{1-\theta}}} ; \nu, \omega, \psi^{\prime}\right)
$$

Consider a history of shock $\left(\omega_{0}, \psi_{1}, \omega_{1}, \psi_{2} \ldots, \omega_{T}, \psi_{T+1}\right)$. Let $k_{*}(t=0), k_{*}(t=1), \ldots, k_{*}(t=T)$ be the optimal sequence of capital for a firm with no long-term mean productivity $\mathcal{V}_{i}=0$. We show by induction that $e^{\frac{\mathcal{V}_{i}}{1-\theta}} k_{*}(t=0), e^{\frac{\mathcal{V}_{i}}{1-\theta}} k_{*}(t=1), \ldots, e^{\frac{\mathcal{V}_{i}}{1-\theta}} k_{*}(t=T)$ is the optimal sequence of capital for the firm with $\mathcal{V}_{i}$.

Assume that: $k_{*}^{i}(t=0)=e^{\frac{\mathcal{V}_{i}}{1-\theta}} k_{*}(t=0)$. At date 1 , the firm with $\mathcal{V}_{i}$ has exogenous state variables $\left(\nu_{1}+\mathcal{V}_{i}, \omega_{1}, \psi_{2+1}\right)$ at date 1 , so that: $k_{*}^{i}(t=1)=k_{*}^{i}\left(e^{\frac{\mathcal{V}_{i}}{1-\theta}} k_{*}(t=0) ; \nu_{1}+\mathcal{V}_{i}, \omega_{1}, \psi_{2}\right)=e^{\frac{\mathcal{V}_{i}}{1-\theta}} k_{*}\left(k_{*}(t=\right.$ $\left.0) ; \nu_{1}, \omega_{1}, \psi_{2}\right)=e^{\frac{\mathcal{V}_{i}}{1-\theta}} k_{*}(t=1)$.

This result is useful for simulation purposes. To simulate the model in the presence of a longrun component in TFP, we just need to simulate the optimal capital from the Bellman problem of a firm with $\mathcal{V}_{i}=0$ and we can then simply calculate the optimal capital stock of a firm facing a similar sequence of shocks by multiplying the capital stock by $e^{\frac{\mathcal{V}_{i}}{1-\theta}}$

\section{A.2 Derivation of model moments}

Our formulation of distorted expectations implies that:

$$
\log \left(\mathbb{F}_{i t-1}\left[e^{\frac{\Phi}{\alpha \theta} \nu_{i t}}\right]\right)=\frac{\Phi}{\alpha \theta}\left((1-\rho) \mathcal{V}_{i}+\rho\left(\nu_{i t-1}+\gamma \omega_{i t-1}\right)+\psi_{i t}\right)+\frac{1}{2}\left(\frac{\Phi}{\alpha \theta}\right)^{2} \sigma_{\omega}^{2}
$$


Since $k_{i t}$ is purchased at date $t-1$, the date $\mathrm{t}-1$ true forecast for date-t sales is:

$$
\mathbb{F}_{i t-1}\left[p_{i t} y_{i t}\right]=\frac{\Omega}{1-(1-\alpha) \theta} \mathbb{F}_{i t-1}\left[e^{\frac{\Phi}{\alpha \theta} \nu_{i t}}\right] k_{i t}^{\Phi}
$$

So that the true log-sales forecast error at date $t$ is:

$$
\begin{aligned}
F E_{i t} & =\log \left(p_{i t} y_{i t}\right)-\log \left(\mathbb{F}_{i t-1}\left[p_{i t} y_{i t}\right]\right) \\
& =\frac{\Phi}{\alpha \theta} \nu_{i t}-\log \left(\mathbb{F}_{i t-1}\left[e^{\frac{\Phi}{\alpha \theta} \nu_{i t}}\right]\right) \\
& =-\frac{\Phi}{\alpha \theta}\left(\gamma \rho \omega_{i t-1}\right)+\frac{\Phi}{\alpha \theta} \omega_{i t}-\frac{1}{2}\left(\frac{\Phi}{\alpha \theta}\right)^{2} \sigma_{\omega}^{2}
\end{aligned}
$$

$\frac{\Phi}{\alpha \theta} \omega_{i t}-\frac{1}{2}\left(\frac{\Phi}{\alpha \theta}\right)^{2} \sigma_{\omega}^{2}$ corresponds to rational expectation errors. $-\frac{\Phi}{\alpha \theta}\left(\gamma \rho \omega_{i t-1}\right)$ corresponds to expectation errors due to managers' distorted forecasts.

Accounting for mis-reporting of true forecasts, observed forecast errors are given by:

$$
\begin{aligned}
\widehat{F E}_{i t} & =\log \left(p_{i t} y_{i t}\right)-\log \left(\widehat{\mathbb{F}}_{i t-1}\left[p_{i t} y_{i t}\right]\right) \\
& =\log \left(p_{i t} y_{i t}\right)-\log \left(\mathbb{F}_{i t-1}\left[p_{i t} y_{i t}\right]\right)-\zeta_{i t} \\
& =-\frac{\Phi}{\alpha \theta}\left(\gamma \rho \omega_{i t-1}\right)+\frac{\Phi}{\alpha \theta} \omega_{i t}-\frac{1}{2}\left(\frac{\Phi}{\alpha \theta}\right)^{2} \sigma_{\omega}^{2}-\zeta_{i t},
\end{aligned}
$$

where $\zeta_{i t}$ is the "noise" introduced by managers in their reported forecasts.

The variance of log-sales forecast errors in the data is therefore given by:

$$
\operatorname{Var}\left[\widehat{F E}_{i t}\right]=\sigma_{\zeta}^{2}+\left(\frac{\Phi}{\alpha \theta}\right)^{2}\left(\left(1+\gamma^{2} \rho^{2}\right) \sigma_{\omega}^{2}\right)
$$

The covariance of date-t and date-t- 1 reported log-sales forecast errors writes:

$$
\operatorname{Cov}\left[\widehat{F E}_{i t}, \widehat{F E}_{i t-1}\right]=-\left(\frac{\Phi}{\alpha \theta}\right)^{2} \gamma \rho \sigma_{\omega}^{2}
$$

Distorted beliefs lead to persistence in forecast errors. An unusually large innovation $\omega_{i t-1}$ implies a positive forecast error today. For an agent over-weighting such unusually large realization (i.e. $\gamma>0$ ), this large innovation means a high forecast for date $t$ sales, which leads, on average, to a negative forecast error at date $t$.

A regression of reported log-sales forecast errors at date $t$ on reported log-sales forecast errors at date $t-1$ leads to a regression coefficient $\kappa_{F E}$ :

$$
\kappa_{F E}=-\frac{\left(\frac{\Phi}{\alpha \theta}\right)^{2} \gamma \rho \sigma_{\omega}^{2}}{\sigma_{\zeta}^{2}+\left(\frac{\Phi}{\alpha \theta}\right)^{2}\left(\left(1+\gamma^{2} \rho^{2}\right) \sigma_{\omega}^{2}\right)}
$$

\section{A.3 Proof of Equation 12}

We first take capital as given, and maximize profit with respect to labor given wage. We obtain:

$$
E B I T_{i t}=(1-\theta(1-\alpha)) Y^{1-\phi} e^{\frac{\Phi z_{i t}}{\alpha}} k^{\Phi}\left(\frac{(1-\alpha) \theta}{w}\right)^{\frac{1-\alpha}{\alpha} \Phi}
$$

In the absence of adjustment costs to capital, the firm selects its capital stock $k_{i t}$ at date $t-1$ to 
maximize date $t$ profits. Given a user cost of capital $R=r+\delta$, this leads to the first-order condition:

$$
\alpha \theta \frac{p_{i t} y_{i t}}{k_{i t}}=R[\underbrace{\frac{e^{\frac{\Phi z_{i t}}{\alpha}}}{\mathbb{F}_{t-1} e^{\frac{\Phi z_{i t}}{\alpha}}}}_{\equiv 1+\tau_{i t}}]
$$

Time to build acts like a wedge $\tau_{i t}$ between the effective cost of capital and the frictionless cost of capital. This wedge has a rational and a bias component. Given that the mean of $z$ is zero and that the TFP shocks $z$ are normally distributed, the log-wedge is given by:

$$
\log \left(1+\tau_{i t}\right)=\frac{\Phi}{\alpha} z_{i t}-\ln \left(\mathbb{F}_{t-1}\left[e^{\frac{\Phi}{\alpha} z_{i t}}\right]\right)=\ln \left(p_{i t} y_{i t}\right)-\ln \left(\mathbb{F}_{t-1}\left[p_{i t} y_{i t}\right]\right)=F E_{i t}
$$

In other words, the log-sales forecast error acts as a capital wedge for the firm. Based on this observation, we know from Hsieh and Klenow (2009) that aggregate TFP depends solely on the wedge dispersion, i.e. on the dispersion of the log-sales forecast errors.

\section{A.4 Formulas for computing aggregate output and TFP}

Write $K^{*}=\int_{i} k_{i}^{*} d i$ the average capital in an economy with $w=1, Y=1$ and $\mathcal{V}_{i}=0$ for all $i$. Similarly, let $Y^{*}=\int_{i} p_{i} y_{i} d i$ be the average sale in this economy. $K^{*}$ and $Y^{*}$ can be found by solving the firm-level problem described in Equation 17 assuming that $A=w=1$.

Recall that, in our general equilibrium model, the sale of firm $i$ in an economy with aggregate output $Y$ is given by: $:^{10}$

$$
p_{i t} y_{i t}=Y^{1-\theta} e^{\nu_{i t}}\left(k_{i t}^{\alpha} l_{i t}^{1-\alpha}\right)^{\theta}
$$

where $\nu_{i t}$ is the revenue productivity in our firm-level model. After labor optimization, given a wage $w$ on the labor market, firm $i$ 's sales at date $t$ is simply:

$$
p_{i t} y_{i t}=(1-(1-\alpha) \theta)^{\frac{1-\alpha}{\alpha} \Phi} \frac{Y^{(1-\theta) \frac{\Phi}{\alpha \theta}}}{w^{\phi \frac{1-\alpha}{\alpha}}} e^{\frac{\Phi}{\alpha \theta} \nu_{i t}} k_{i t}^{\Phi}=\underbrace{\left(\frac{e^{\frac{\Phi}{\alpha \theta} \mathcal{V}_{i}} Y^{(1-\theta) \frac{\Phi}{\alpha \theta}}}{w^{\phi \frac{1-\alpha}{\alpha}}}\right)}_{=e^{\frac{\Phi}{\alpha \theta} \lambda_{i}}}(1-\alpha) \theta)^{\frac{1-\alpha}{\alpha} \Phi} e^{\frac{\Phi}{\alpha \theta}\left(\nu_{i t}-\mathcal{V}_{i}\right)} k_{i t}^{\Phi}
$$

Using the same proof as in Section A.1, it is direct to show that, for a firm with long-term productivity $\mathcal{V}_{i}$ and in an economy with aggregate output $Y$ and wage $w$, the optimal capital stock for a firm $i$ is simply given by:

$$
k_{i t}=e^{\frac{\lambda_{i}}{1-\theta}} k_{i t}^{*},
$$

where $k_{i t}^{*}$ is the capital stock chosen by a firm with a similar history of shocks $(\omega, \psi)$, a long-term productivity of $\mathcal{V}_{i}=0$ and $w=Y=1$. Recall that $e^{\frac{\lambda_{i}}{1-\theta}}=\frac{e^{\frac{\mathcal{V}_{i}}{1-\theta}} Y}{w^{\frac{(1-\alpha) \theta}{1-\theta}}}$.

Therefore, since $k_{i t}^{*}$ is orthogonal to $\mathcal{V}_{i}$, the aggregate capital stock is given by:

$$
K=\frac{Y}{w^{\frac{(1-\alpha) \theta}{1-\theta}}}\left[\int_{i} e^{\frac{\mathcal{V}_{i}}{1-\theta}} d i\right] K^{*}
$$

In a similar way, we can relate the sales of firm $i$, with long-term productivity $\mathcal{V}_{i}$ in the actual economy $(w, Y)$, to the sales of a firm with a similar history of shocks $(\omega, \psi)$, with long-term productivity

\footnotetext{
${ }^{10} \mathrm{We}$ omit the constant B for convenience, without loss of generality.
} 
0 and in an economy with $w=Y=1$ :

$$
p_{i t} y_{i t}=\underbrace{e^{\frac{\Phi}{\alpha \theta} \lambda_{i}} \times e^{\frac{\Phi}{1-\theta} \lambda_{i}}}_{=e^{\frac{\lambda_{i}}{1-\theta}}} p_{i t}^{*} y_{i t}^{*}
$$

Therefore, since $p_{i t}^{*} y_{i t}^{*}$ is orthogonal to $\mathcal{V}_{i}$, we obtain a simple expression for the equilibrium wage:

$$
w^{\frac{(1-\alpha) \theta}{1-\theta}}=\left[\int_{i} e^{\frac{\mathcal{V}_{i}}{1-\theta}} d i\right] Y^{*}
$$

In the actual economy, firm $i$ labor demand is simply:

$$
l_{i t}=\left(\frac{(1-\alpha) \theta}{w}\right) p_{i t} y_{i t}
$$

Therefore, aggregate labor demand writes:

$$
L^{d}=\left(\frac{(1-\alpha) \theta}{w}\right) Y
$$

In equilibrium, labor supply equals labor demand:

$$
\frac{L_{0}}{w_{0}^{\epsilon}} w^{1+\epsilon}=(1-\alpha) \theta Y
$$

By substituting the equilibrium wage, one can derive an expression for aggregate output as a function of $Y^{*}$ :

$$
Y=\frac{L_{0}}{(1-\alpha) \theta w_{0}^{\epsilon}}\left(\left[\int_{i} e^{\frac{\mathcal{V}_{i}}{1-\theta}} d i\right] Y^{*}\right)^{(1+\epsilon) \frac{1-\theta}{(1-\alpha) \theta}}
$$

We can similarly relate aggregate TFP to $K^{*}$ and $Y^{*}$ :

$$
T F P=((1-\alpha) \theta)^{1-\alpha}\left[\int_{i} e^{\frac{\mathcal{V}_{i}}{1-\theta}} d i\right]^{\frac{\theta}{1-\theta}}\left(Y^{*}\right)^{\frac{1-(1-\alpha) \theta}{\theta}}\left(K^{*}\right)^{-\alpha}
$$

Let $K_{0}^{*}=\int_{i} k_{i}^{*, 0} d i$ be the average capital stock for rational firms with $w=Y=1$ and $\mathcal{V}_{i}=0$, for all $i$. Similarly, let $Y_{0}^{*}=\int_{i} p_{i}^{*, 0} y_{i}^{*, 0} d i$ be the average sales in this economy with rational firms. Aggregate TFP in general equilibrium with rational firms is simply given by:

$$
T F P_{0}=((1-\alpha) \theta)^{1-\alpha}\left[\int_{i} e^{\frac{\mathcal{V}_{i}}{1-\theta}} d i\right]^{\frac{\theta}{1-\theta}}\left(Y_{0}^{*}\right)^{\frac{1-(1-\alpha) \theta}{\theta}}\left(K_{0}^{*}\right)^{-\alpha}
$$

Therefore, the TFP loss due to distortion in forecasts can simply be expressed as:

$$
\log \left(T F P_{0}\right)-\log (T F P)=\alpha\left(\log \left(K^{*}\right)-\log \left(K_{0}^{*}\right)\right)+\frac{1-(1-\alpha) \theta}{\theta}\left(\log \left(Y_{0}^{*}\right)-\log \left(Y^{*}\right)\right)
$$

\section{A.5 Optimism / pessimism bias}

Consider a firm with a fixed belief $b_{i}$ and a long-term productivity $\mathcal{V}_{i}$, so that:

$$
\nu_{i t}=\rho \nu_{i t-1}+(1-\rho) \mathcal{V}_{i}+\psi_{i t}+\omega_{i t} \text { and: } \nu_{i t} \stackrel{\mathbb{P}}{\sim} \mathcal{N}\left(\rho \nu_{i t-1}+(1-\rho)\left(\mathcal{V}_{i}+b_{i}\right), \sigma_{\omega}^{2}\right)
$$

The firm's optimization problem admits the following Bellman representation: 


$$
\begin{aligned}
& V^{i}\left(k ; z, \omega, \psi^{\prime}\right)=\max _{k^{\prime}}\left\{\Omega e^{\frac{\Phi}{\alpha \theta} z} k^{\phi}-\left(k^{\prime}-(1-\delta) k\right)-c_{k} \frac{\left(k^{\prime}-(1-\delta) k\right)^{2}}{k}\right. \\
& \left.+\frac{1}{1+r} \mathbb{F}\left[V^{i}\left(k^{\prime} ; z^{\prime}, \omega^{\prime}, \psi^{\prime \prime}\right) \mid\left(z, \omega, \psi^{\prime}\right)\right]\right\}
\end{aligned}
$$

with:

$$
\left(\begin{array}{c}
z^{\prime} \\
\omega^{\prime}
\end{array}\right) \stackrel{\mathbb{F}}{\sim} \mathcal{N}\left(\left(\begin{array}{c}
(1-\rho)\left(\mathcal{V}_{i}+b_{i}\right)+\rho z+\gamma \rho \omega+\psi^{\prime} \\
0
\end{array}\right),\left(\begin{array}{cc}
\sigma_{\omega}^{2} & \sigma_{\omega}^{2} \\
\sigma_{\omega}^{2} & \sigma_{\omega}^{2}
\end{array}\right)\right) \text { and: } \psi^{\prime \prime} \stackrel{\mathbb{P}}{\sim} \mathcal{N}\left(0, \sigma_{\psi}^{2}\right)
$$

Using the notations from Appendix A.1, it is direct to see that the optimal policy for this firm can be expressed as a function of the optimal policy of a firm with $b_{i}=0$ and $\mathcal{V}_{i}=0$ :

$$
k_{*}^{i}\left(k ; \nu+\mathcal{V}_{i}+b_{i}, \omega, \psi^{\prime}\right)=e^{\frac{\mathcal{V}_{i}+b_{i}}{1-\theta}} \times k_{*}\left(\frac{k}{e^{\frac{\mathcal{V}_{i}+b_{i}}{1-\theta}}} ; \nu, \omega, \psi^{\prime}\right)
$$

However, note that unlike in Appendix A.1, given a history of shock $\left.\omega_{0}, \psi_{1}, \omega_{1}, \psi_{2} \ldots, \omega_{T}, \psi_{T+1}\right)$, the capital stock of a firm with $b_{i}$ and $\mathcal{V}_{i}$ is not a constant multiple of the capital stock of the firm with $b_{i}=0$ and $\mathcal{V}_{i}=0$. This is because if $\nu_{1}$ is the productivity of the firm with $b_{i}=0$ and $\mathcal{V}_{i}=0$ at date 1 , the productivity of the firm with $b_{i}$ and $\mathcal{V}_{i}$ at date 1 is $\nu_{1}+\mathcal{V}_{i}$, not $\nu_{1}+\mathcal{V}_{i}+b_{i}$.

To numerically solve the model with a fixed bias in belief, we first find the optimal policy function for a firm with no biased belief $\left(b_{i}=0\right)$ and no long-run mean in productivity $\left(\mathcal{V}_{i}=0\right), k_{*}\left(k ; \nu, \omega, \psi^{\prime}\right)$. We then draw a history of shock $\left(\omega_{i t}, \psi_{i t}\right)_{t}$, which allows us to calculate a history of actual TFP $\left(\nu_{i t}\right)_{t}$, with $\nu_{i t}=\rho \nu_{i t-1}+(1-\rho) \mathcal{V}_{i}+\omega_{i t}+\psi_{i t}$. We then calculate the optimal capital stock of the firm recursively through:

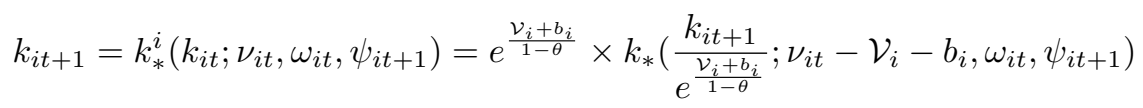

To calculate aggregate TFP in this economy, we use a similar approach to the one described in Appendix A.4. We start by computing the average steady-state capital in the economy with $w=1$, $Y=1$ and $\mathcal{V}_{i}=0$ for all $i$, but with $\gamma$ and $\sigma_{b}$ at their estimated value. Denote this steady state capital by $K^{*}=\int_{i} k_{i}^{*} d i$. Similarly, let $Y^{*}=\int_{i} p_{i} y_{i} d i$ be the average steady-state sales in this economy. Both $K^{*}$ and $Y^{*}$ can be found by solving the model in the way described above.

Recall that, in our general equilibrium model, the sale of firm $i$ in an economy with aggregate output $Y$ is given by: ${ }^{11}$

$$
p_{i t} y_{i t}=Y^{1-\theta} e^{\nu_{i t}}\left(k_{i t}^{\alpha} l_{i t}^{1-\alpha}\right)^{\theta}
$$

where $\nu_{i t}$ is the revenue productivity in our firm-level model. After labor optimization, given a wage $w$ on the labor market, firm $i$ 's sales at date $t$ is simply:

$$
p_{i t} y_{i t}=(1-(1-\alpha) \theta)^{\frac{1-\alpha}{\alpha} \Phi} \frac{Y^{(1-\theta) \frac{\Phi}{\alpha \theta}}}{w^{\phi \frac{1-\alpha}{\alpha}}} e^{\frac{\Phi}{\alpha \theta} \nu_{i t}} k_{i t}^{\Phi}=\underbrace{\left(\frac{e^{\frac{\Phi}{\alpha \theta}} \mathcal{V}_{i} Y^{(1-\theta) \frac{\Phi}{\alpha \theta}}}{w^{\frac{1-\alpha}{\alpha}}}\right)}_{=e^{\frac{\Phi}{\alpha \theta} \lambda_{i}}}(1-\alpha) \theta)^{\frac{1-\alpha}{\alpha} \Phi} e^{\frac{\Phi}{\alpha \theta}\left(\nu_{i t}-\mathcal{V}_{i}\right)} k_{i t}^{\Phi}
$$

We now relate the optimal investment decision of firms in an economy with $w=1=Y$ and $\mathcal{V}_{i}=0$ to that of an economy with arbitrary $w$ and $Y$ and a long-term mean in TFP $\mathcal{V}_{i}$.

Consider first the Bellman problem of the firm with long-term productivity of $\mathcal{V}_{i}=0$, bias $(b)$ and

${ }^{11}$ We omit the constant B for convenience, without loss of generality. 
$w=Y=1:$

$$
\begin{gathered}
V_{b}\left(k ; \nu, \omega, \psi^{\prime}\right)=\max _{k^{\prime}}\left\{\Omega e^{\frac{\Phi}{\alpha \theta} \nu} k^{\phi}-\left(k^{\prime}-(1-\delta) k\right)-c_{k} \frac{\left(k^{\prime}-(1-\delta) k\right)^{2}}{k}\right. \\
\left.+\frac{1}{1+r} \mathbb{F}\left[V\left(k^{\prime} ; \nu^{\prime}, \omega^{\prime}, \psi^{\prime \prime}\right) \mid\left(\nu, \omega, \psi^{\prime}\right)\right]\right\}
\end{gathered}
$$

with:

$$
\left(\begin{array}{c}
\nu^{\prime} \\
\omega^{\prime}
\end{array}\right) \stackrel{\mathbb{F}}{\sim} \mathcal{N}\left(\left(\begin{array}{c}
\rho \nu+(1-\rho) b+\gamma \rho \omega+\psi^{\prime} \\
0
\end{array}\right),\left(\begin{array}{cc}
\sigma_{\omega}^{2} & \sigma_{\omega}^{2} \\
\sigma_{\omega}^{2} & \sigma_{\omega}^{2}
\end{array}\right)\right) \text { and: } \psi^{\prime \prime} \stackrel{\mathbb{F}}{\sim} \mathcal{N}\left(0, \sigma_{\psi}^{2}\right), \text { and }
$$

$\Omega=(1-(1-\alpha) \theta)$.

Let $k_{b}^{*}\left(k ; \nu, \omega \psi^{\prime}\right)$ be the optimal policy function of this problem. Consider now the problem of a firm with the same bias $b$, but with $w \neq 1, Y \neq 1$ and $\mathcal{V}_{i} \neq 0$ :

$$
\begin{aligned}
V_{b}^{i}\left(k ; z, \omega, \psi^{\prime}\right)=\max _{k^{\prime}}\{( & \left.\frac{Y^{1-\Phi}}{w^{\frac{1-\alpha}{\alpha} \Phi}}\right) \Omega e^{\frac{\Phi}{\alpha \theta} z} k^{\phi}-\left(k^{\prime}-(1-\delta) k\right)-c_{k} \frac{\left(k^{\prime}-(1-\delta) k\right)^{2}}{k} \\
& \left.+\frac{1}{1+r} \mathbb{F}\left[V^{i}\left(k^{\prime} ; z^{\prime}, \omega^{\prime}, \psi^{\prime \prime}\right) \mid\left(z, \omega, \psi^{\prime}\right)\right]\right\}
\end{aligned}
$$

with:

$$
\left(\begin{array}{c}
z^{\prime} \\
\omega^{\prime}
\end{array}\right) \stackrel{\mathbb{F}}{\sim} \mathcal{N}\left(\left(\begin{array}{c}
(1-\rho)\left(\mathcal{V}_{i}+b\right)+\rho z+\gamma \rho \omega+\psi^{\prime} \\
0
\end{array}\right),\left(\begin{array}{cc}
\sigma_{\omega}^{2} & \sigma_{\omega}^{2} \\
\sigma_{\omega}^{2} & \sigma_{\omega}^{2}
\end{array}\right)\right) \text { and: } \psi^{\prime \prime} \stackrel{\mathbb{F}}{\sim} \mathcal{N}\left(0, \sigma_{\psi}^{2}\right)
$$

Define $\nu=z-\mathcal{V}_{i}$. We can rewrite the Bellman problem as a function of $\nu$ instead of $z$ :

$$
\begin{aligned}
V^{i}\left(k ; \nu+\mathcal{V}_{i}, \omega, \psi^{\prime}\right)=\max _{k^{\prime}}\{ & \left(\frac{Y^{1-\Phi}}{w^{\frac{1-\alpha}{\alpha} \Phi}}\right) \Omega e^{\frac{\Phi}{\alpha \theta}\left(\nu+\mathcal{V}_{i}\right)} k^{\phi}-\left(k^{\prime}-(1-\delta) k\right)-c_{k} \frac{\left(k^{\prime}-(1-\delta) k\right)^{2}}{k} \\
& \left.+\frac{1}{1+r} \mathbb{F}\left[V^{i}\left(k^{\prime} ; \nu^{\prime}+\mathcal{V}_{i}, \omega^{\prime}, \psi^{\prime \prime}\right) \mid\left(\nu, \omega, \psi^{\prime}\right)\right]\right\}
\end{aligned}
$$

with:

$$
\left(\begin{array}{c}
\nu^{\prime} \\
\omega^{\prime}
\end{array}\right) \stackrel{\mathbb{F}}{\sim} \mathcal{N}\left(\left(\begin{array}{c}
\rho \nu+(1-\rho) b+\gamma \rho \omega+\psi^{\prime} \\
0
\end{array}\right),\left(\begin{array}{cc}
\sigma_{\omega}^{2} & \sigma_{\omega}^{2} \\
\sigma_{\omega}^{2} & \sigma_{\omega}^{2}
\end{array}\right)\right) \text { and: } \psi^{\prime \prime} \stackrel{\mathbb{F}}{\sim} \mathcal{N}\left(0, \sigma_{\psi}^{2}\right)
$$

We can rewrite this previous problem in a simpler fashion:

$$
\begin{aligned}
& V^{i}\left(k ; \nu+\mathcal{V}_{i}, \omega, \psi^{\prime}\right)=\max _{k^{\prime}}\left\{e ^ { \frac { \lambda _ { i } } { 1 - \theta } } \left(\Omega e^{\frac{\Phi}{\alpha \theta} \nu}\left(\frac{k}{e^{\frac{\lambda^{i}}{1-\theta}}}\right)^{\phi}-\left(\left(\frac{k^{\prime}}{e^{\frac{\lambda_{i}}{1-\theta}}}\right)-(1-\delta)\left(\frac{k}{e^{\frac{\lambda_{i}}{1-\theta}}}\right)\right)\right.\right. \\
& \left.\left.-c_{k} \frac{\left(\left(\frac{k^{\prime}}{e^{\frac{\lambda_{i}}{1-\theta}}}\right)-(1-\delta)\left(\frac{k}{e^{\frac{\lambda_{i}}{1-\theta}}}\right)\right)^{2}}{\left(\frac{k}{e^{\frac{\lambda_{i}}{1-\theta}}}\right)}\right)+\frac{1}{1+r} \mathbb{F}\left[V^{i}\left(k^{\prime} ; \nu^{\prime}+\mathcal{V}_{i}, \omega^{\prime}, \psi^{\prime \prime}\right) \mid\left(\nu, \omega, \psi^{\prime}\right)\right]\right\}
\end{aligned}
$$

with:

$$
\begin{aligned}
& \left(\begin{array}{c}
\nu^{\prime} \\
\omega^{\prime}
\end{array}\right) \stackrel{\mathbb{F}}{\sim} \mathcal{N}\left(\left(\begin{array}{c}
\rho \nu+(1-\rho) b+\gamma \rho \omega+\psi^{\prime} \\
0
\end{array}\right),\left(\begin{array}{cc}
\sigma_{\omega}^{2} & \sigma_{\omega}^{2} \\
\sigma_{\omega}^{2} & \sigma_{\omega}^{2}
\end{array}\right)\right) \text { and: } \psi^{\prime \prime} \stackrel{\mathbb{F}}{\sim} \mathcal{N}\left(0, \sigma_{\psi}^{2}\right) \text {, and: } \\
& e^{\frac{\lambda_{i}}{1-\theta}}=\frac{e^{\frac{\mathcal{V}_{i}}{1-\theta}} Y}{w^{\frac{(1-\alpha) \theta}{1-\theta}}}
\end{aligned}
$$


This last representation is equivalent to:

$$
\begin{aligned}
\left(\frac{V^{i}\left(k ; \nu+\mathcal{V}_{i}, \omega, \psi^{\prime}\right)}{e^{\frac{\lambda_{i}}{1-\theta}}}\right)= & \max _{k^{\prime}}\left\{\left(\Omega e^{\frac{\Phi}{\alpha \theta} \nu}\left(\frac{k}{e^{\frac{\lambda_{i}}{1-\theta}}}\right)^{\phi}-\left(\left(\frac{k^{\prime}}{e^{\frac{\lambda_{i}}{1-\theta}}}\right)-(1-\delta)\left(\frac{k}{e^{\frac{\lambda_{i}}{1-\theta}}}\right)\right)\right.\right. \\
& \left.\left.\left.-c_{k} \frac{\left.\left.\left(\left(\frac{k^{\prime}}{e^{\frac{\lambda_{i}}{1-\theta}}}\right)-(1-\delta)\left(\frac{k}{e^{\frac{\lambda_{i}}{1-\theta}}}\right)\right)^{2}\right)+\frac{1}{1+r} \mathbb{F}\left[\left(\frac{V^{i}\left(k^{\prime} ; \nu^{\prime}+\mathcal{V}_{i}, \omega^{\prime}, \psi^{\prime \prime}\right)}{e^{\frac{\lambda_{i}}{1-\theta}}}\right) \mid\left(\nu, \omega, \psi^{\prime}\right)\right]\right\}}{e^{\frac{\lambda_{i}}{1-\theta}}}\right)\right]\right\}
\end{aligned}
$$

with:

$$
\left(\begin{array}{c}
\nu^{\prime} \\
\omega^{\prime}
\end{array}\right) \stackrel{\mathbb{F}}{\sim} \mathcal{N}\left(\left(\begin{array}{c}
\rho \nu+(1-\rho) b+\gamma \rho \omega+\psi^{\prime} \\
0
\end{array}\right),\left(\begin{array}{cc}
\sigma_{\omega}^{2} & \sigma_{\omega}^{2} \\
\sigma_{\omega}^{2} & \sigma_{\omega}^{2}
\end{array}\right)\right) \text { and: } \psi^{\prime \prime} \stackrel{\mathbb{F}}{\sim} \mathcal{N}\left(0, \sigma_{\psi}^{2}\right)
$$

It is clear from this equation that:

$$
k_{b}^{i, *}\left(k ; \nu+\mathcal{V}_{i}, \omega, \psi^{\prime}\right)=e^{\frac{\lambda_{i}}{1-\theta}} \times k_{b}^{*}\left(\frac{k}{e^{\frac{\lambda^{i}}{1-\theta}}} ; \nu, \omega, \psi^{\prime}\right)
$$

Consider a firm facing a history of shock $\left(\omega_{t}, \psi_{t}\right)$.

It is direct to see from the previous result that for a firm with long-term productivity $\mathcal{V}_{i}$, bias $b_{i}$ and in an economy with aggregate output $Y$ and wage $w$, the optimal capital stock is given by:

$$
k_{i t}=e^{\frac{\lambda_{i}}{1-\theta}} k_{i t}^{*},
$$

where $k_{i t}^{*}$ is the capital stock chosen by a firm with a similar history of shocks $\left(\omega_{i t}, \psi_{i t}\right)$, similar forecasting biases $\left(b_{i}\right.$ and $\gamma$ ) but with a long-term productivity of $\mathcal{V}_{i}=0$, and $w=Y=1$.

We can show this result by induction. Consider a history of shocks $\left(\omega_{i t}, \psi_{i t}\right)_{t}$. Assume that $k_{i 0}=$ $e^{\frac{\lambda_{i}}{1-\theta}} k_{i t}^{*}$. At date 1 , if $\nu_{i 1}$ is the productivity of the firm with $\mathcal{V}_{i}=0$, the productivity of the firm with $\mathcal{V}_{i}$ is $\nu_{i 1}+\mathcal{V}_{i}$. As a result, we know from our previous result that:

$$
\begin{aligned}
k_{i 1}=k_{b}^{i, *}\left(k_{i 0} ; \nu_{i 1}+\mathcal{V}_{i}, \omega_{i 1}, \psi_{i 2}\right) & =e^{\frac{\lambda_{i}}{1-\theta}} \times k_{b}^{*}\left(\frac{k_{i 0}}{e^{\frac{\lambda^{i}}{1-\theta}}} ; \nu_{i 1}, \omega_{1 i}, \psi_{i 2}\right) \\
& =e^{\frac{\lambda_{i}}{1-\theta}} \times k_{b}^{*}\left(k_{i 0}^{*} ; \nu_{i 1}, \omega_{1 i}, \psi_{i 2}\right) \\
& =e^{\frac{\lambda_{i}}{1-\theta}} k_{i 1}^{*}
\end{aligned}
$$

In a similar way, we can relate the sales of firm $i$, with long-term productivity $\mathcal{V}_{i}$ and bias $b_{i}$ in the actual economy $(w, Y)$, to the sales of a firm with a similar history of shocks $(\omega, \psi)$, with long-term productivity 0 and in an economy with $w=Y=1$ :

$$
p_{i t} y_{i t}=\underbrace{e^{\frac{\Phi}{\alpha \theta} \lambda_{i}} \times e^{\frac{\Phi}{1-\theta} \lambda_{i}}}_{=e^{\frac{\lambda_{i}}{1-\theta}}} p_{i t}^{*} y_{i t}^{*}
$$

Therefore, since $p_{i t}^{*} y_{i t}^{*}$ is orthogonal to $\mathcal{V}_{i}$, we obtain a simple expression for the equilibrium wage:

$$
w^{\frac{(1-\alpha) \theta}{1-\theta}}=\left[\int_{i} e^{\frac{\mathcal{V}_{i}}{1-\theta}} d i\right] Y^{*}
$$

In the actual economy, firm $i$ labor demand is simply:

$$
l_{i t}=\left(\frac{(1-\alpha) \theta}{w}\right) p_{i t} y_{i t}
$$


Therefore, aggregate labor demand writes:

$$
L^{d}=\left(\frac{(1-\alpha) \theta}{w}\right) Y
$$

In equilibrium, labor supply equals labor demand:

$$
\frac{L_{0}}{w_{0}^{\epsilon}} w^{1+\epsilon}=(1-\alpha) \theta Y
$$

By substituting the equilibrium wage, one can derive an expression for aggregate output as a function of $Y^{*}$ :

$$
Y=\frac{L_{0}}{(1-\alpha) \theta w_{0}^{\epsilon}}\left(\left[\int_{i} e^{\frac{\mathcal{V}_{i}}{1-\theta}} d i\right] Y^{*}\right)^{(1+\epsilon) \frac{1-\theta}{(1-\alpha) \theta}}
$$

We can similarly relate aggregate TFP to $K^{*}$ and $Y *$ :

$$
T F P=((1-\alpha) \theta)^{1-\alpha}\left[\int_{i} e^{\frac{\mathcal{V}_{i}}{1-\theta}} d i\right]^{\frac{\theta}{1-\theta}}\left(Y^{*}\right)^{\frac{1-(1-\alpha) \theta}{\theta}}\left(K^{*}\right)^{-\alpha}
$$

To calculate the TFP losses from distorted beliefs, we can simply simulate the model assuming $\gamma=\sigma_{b}=0, Y=w=1$ and $\sigma_{\mathcal{V}}=0$, calculate the average capital $K_{0}^{*}$ and sales $Y_{0}^{*}$ in this economy, and compute:

$$
\Delta \log (T F P)=\alpha\left(\log \left(K^{*}\right)-\log \left(K_{0}^{*}\right)\right)+\frac{1-(1-\alpha) \theta}{\theta}\left(\log \left(Y_{0}^{*}\right)-\log \left(Y^{*}\right)\right)
$$

